\begin{tabular}{|c|c|c|c|c|}
\hline $5 \mathrm{AE}$ & $\begin{array}{l}\text { REUISTA DE ESTUDIOS } \\
\text { ALBACETEUSES }\end{array}$ & $\begin{array}{c}\text { Número } \\
14\end{array}$ & $\begin{array}{c}\text { Páginas } \\
155-210\end{array}$ & $\begin{array}{c}\text { Año } \\
2020\end{array}$ \\
\hline
\end{tabular}

\title{
PRONTUARIO DE LA NATURALEZA ALBACETENSE
}

\author{
Recopilado por Domingo BLANCO SIDERA* \\ y Juan PICAZO TALAVERA*
}

* Instituto de Estudios Albacetenses "Don Juan Manuel"

Correo electrónico: prontuariosabuco@iealbacetenses.com 

El prontuario de la naturaleza albacetense pretende recoger aquellos conocimientos inéditos, o publicados en otros medios, sobre la naturaleza de Albacete que, por su carácter puntual (citas), no tienen cabida en otras secciones de la revista SABUCO.

Los criterios de selección son difíciles de unificar para todos los grupos taxonómicos. En general hemos utilizado los siguientes: primeras citas de especies para la provincia, especies escasas a nivel provincial, especies incluidas en catálogos de especies protegidas en la normativa vigente o en las diferentes listas rojas publicadas, ampliación de áreas de distribución, número relevante de individuos, observaciones fenológicas inusuales o individuos vistos fuera de su área de distribución conocida, datos relevantes sobre la ecología o comportamiento de las especies.

En todos los casos, y especialmente para especies catalogadas "en peligro de extinción”, se omitirán detalles que pudieran suponer riesgo para sus poblaciones.

Las citas que necesiten homologación por los correspondientes comités biológicos de ámbito nacional, serán reseñadas con un asterisco $\left(^{*}\right)$.

Sin perjuicio de la selección realizada y aceptación de citas, éstas han sido remitidas voluntariamente por sus autores (indicados entre paréntesis y en negrita) y a ellos corresponde la veracidad de los datos reflejados.

Se recogen también citas que forman parte de artículos en otras publicaciones científicas, indicando las referencias bibliográficas correspondientes.

Dada la proliferación de medios digitales en los que se publican citas de distintos grupos taxonómicos y con diferentes ámbitos geográficos, desde SABUCO se intenta recoger toda la información referente a la provincia que aparezca en ellos. Agradecemos que los autores de citas en otros medios nos las remitan para incluirlas en nuestro prontuario, indicando siempre la referencia en la que se hizo su publicación.

Para el envío de citas para el prontuario es recomendable utilizar la plantilla que se puede descargar de nuestra página web, desde el apartado 2 (Envío de originales) de las normas de publicación de SABUCO.

Ejemplo de cita recomendada: Salvador, E. J. (2020). Comatricha nigra. En Blanco Sidera, D. y Picazo Talavera, J. (rec.): Prontuario de la Naturaleza Albacetense. Sabuco, 14: 155-210. 


\section{PROTOZOA \\ División Mixomicota}

Clase MYXOMICETES

\section{Orden STEMONITALES}

$\underline{\text { Familia Stemonitidaceae }}$

Comatricha nigra (Pers.) J. Schröt., 1886

Mixomicete reconocible por esporangios globosos a subcilíndricos, de color pardo oscuro, ferruginoso cuando maduran liberando las esporas. Unidos al sustrato por un largo filamento. Especie frecuente, citada anteriormente por Gracia et al. (1981).

Año 2019: 28 de diciembre, Villalgordo del Júcar, sobre madera de Populus alba L. (Emilio J. Salvador). Figura 1.

\section{Orden PHYSARALES}

\section{$\underline{\text { Familia Didimiaceae }}$}

Didymium squamulosum (Alb. \& Schwein.) Fr., 1818

Roldán y Honrubia (1992) lo dan como abundante, creciendo sobre restos de plantas y excrementos de herbívoros. A pesar de ello hay pocos registros publicados.

Año 2019: 28 de diciembre en Villalgordo del Júcar, sobre madera de Populus alba L. (Emilio J. Salvador). Figura 2.

\section{$\underline{\text { Familia Physaraceae }}$}

Physarum album (Bull.) Chevall., 1826

Especie de mixomicete no citada anteriormente en la provincia.

Año 2020: encontrado el 3 de enero en Villalgordo del Júcar sobre madera de Populus alba L. (Emilio J. Salvador). Figura 3.

Physarum leucophaeum Fr., in Fries \& Nordholm, 1818

Sinónimo: Physarum nutans subsp. leucophaeum (Fr.) G. Lister, 1911 


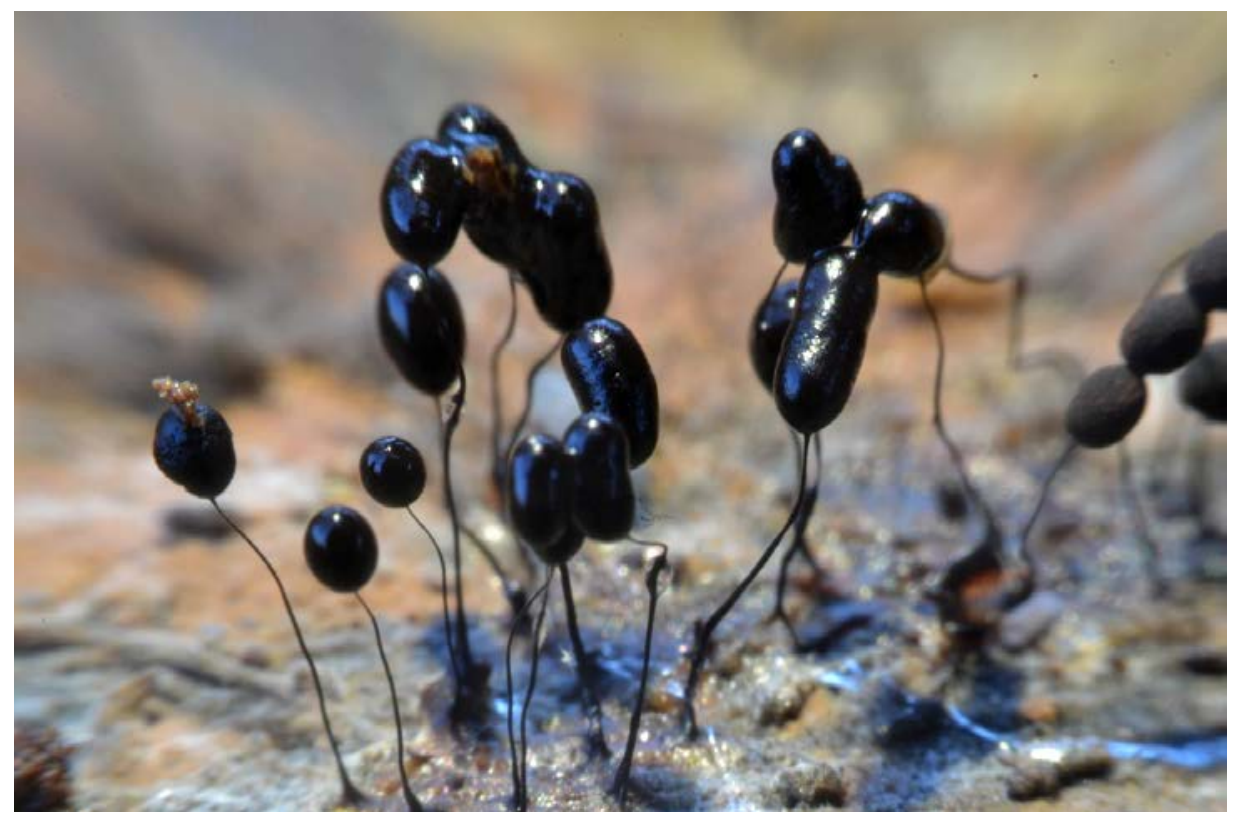

Figura 1. Comatricha nigra. Fotografía: Emilio J. Salvador.

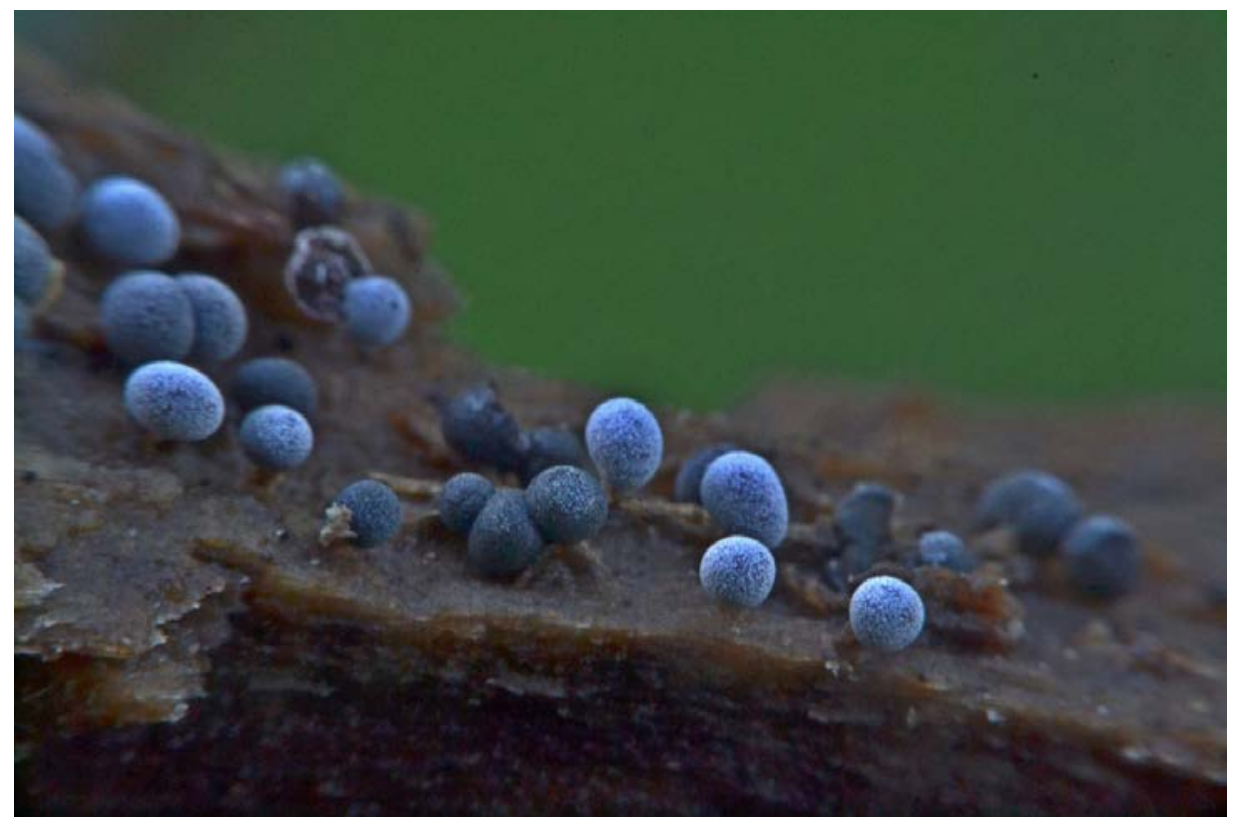

Figura 2. Didymium squamulosum. Fotografía: Emilio J. Salvador. 


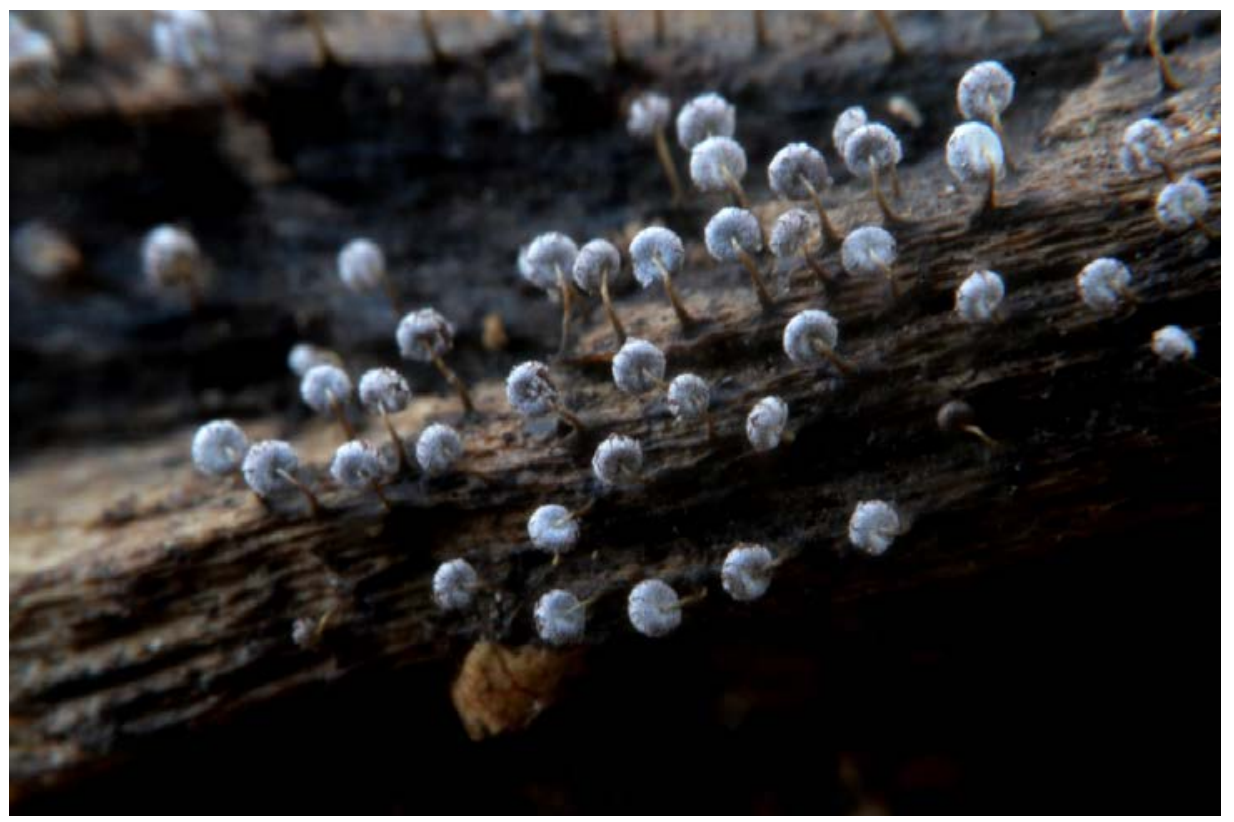

Figura 3. Physarum album. Fotografía: Emilio J. Salvador.

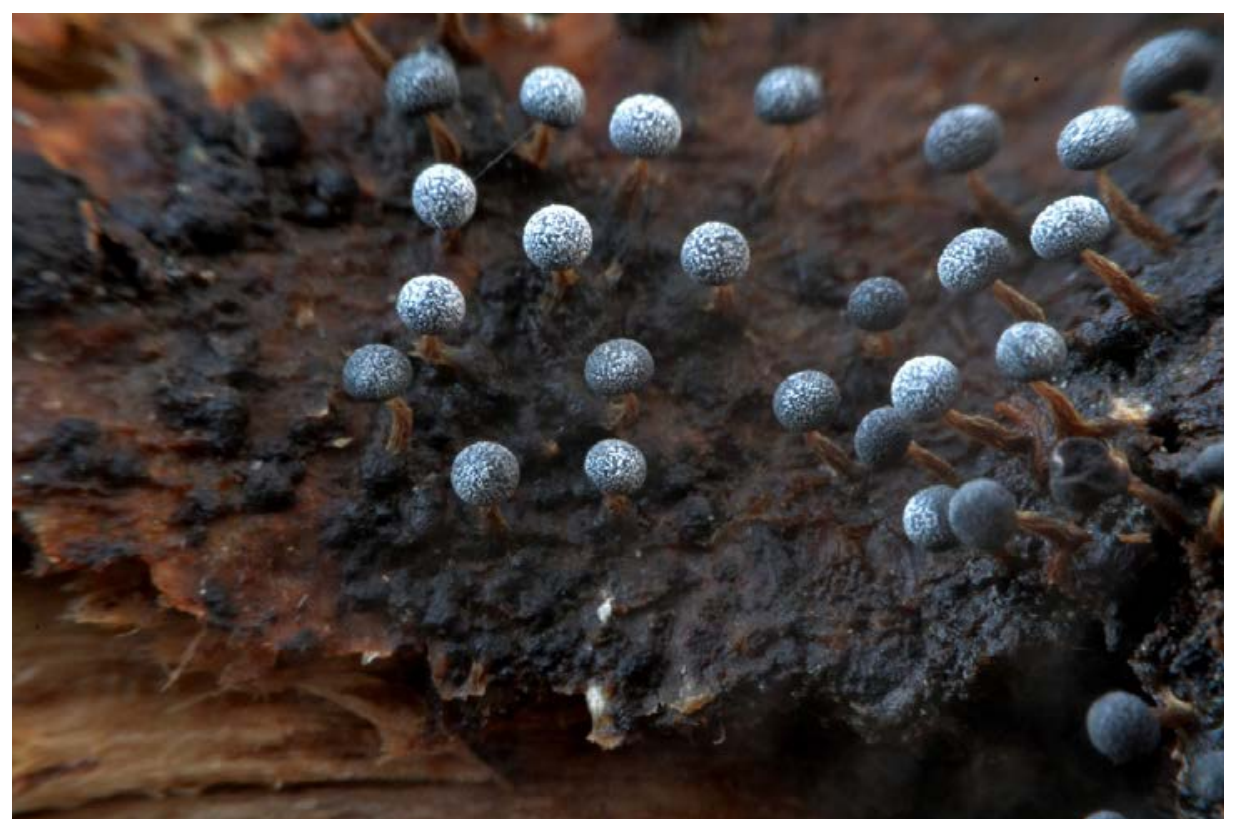

Figura 4. Physarum leucophaeum. Fotografía: Emilio J. Salvador. 
Nueva localidad para esta especie de mixomicete, ya citada por LópezSánchez et al. (1986). Roldán y Honrubia (1992) la dan como poco frecuente en la provincia con citas en Socovos y Riópar.

Año 2020: 3 de enero en Villalgordo del Júcar, sobre madera de Populus alba L. (Emilio J. Salvador). Figura 4.

$\underline{\text { Familia Stemonitidaceae }}$

Stemonitis axifera (Bull.) T. Macbr., 1889

Especie no citada en la provincia.

Año 2020: 7 de junio, Fuensanta, sobre madera de Quercus faginea Lam. (Emilio J. Salvador). Figura 5.

\section{Orden TRICHIALES}

\section{Familia Trichiaceae}

Trichia varia (Pers. ex J.F. Gmel.) Pers., 1794

Mixomicete poco frecuente. Aparece sobre madera muerta en zonas muy húmedas. Citada anteriormente por Gracia et al. (1981)

Año 2020: 3 de enero, en Villalgordo del Júcar, sobre madera de Populus alba L. (Emilio J. Salvador). Figura 6. 


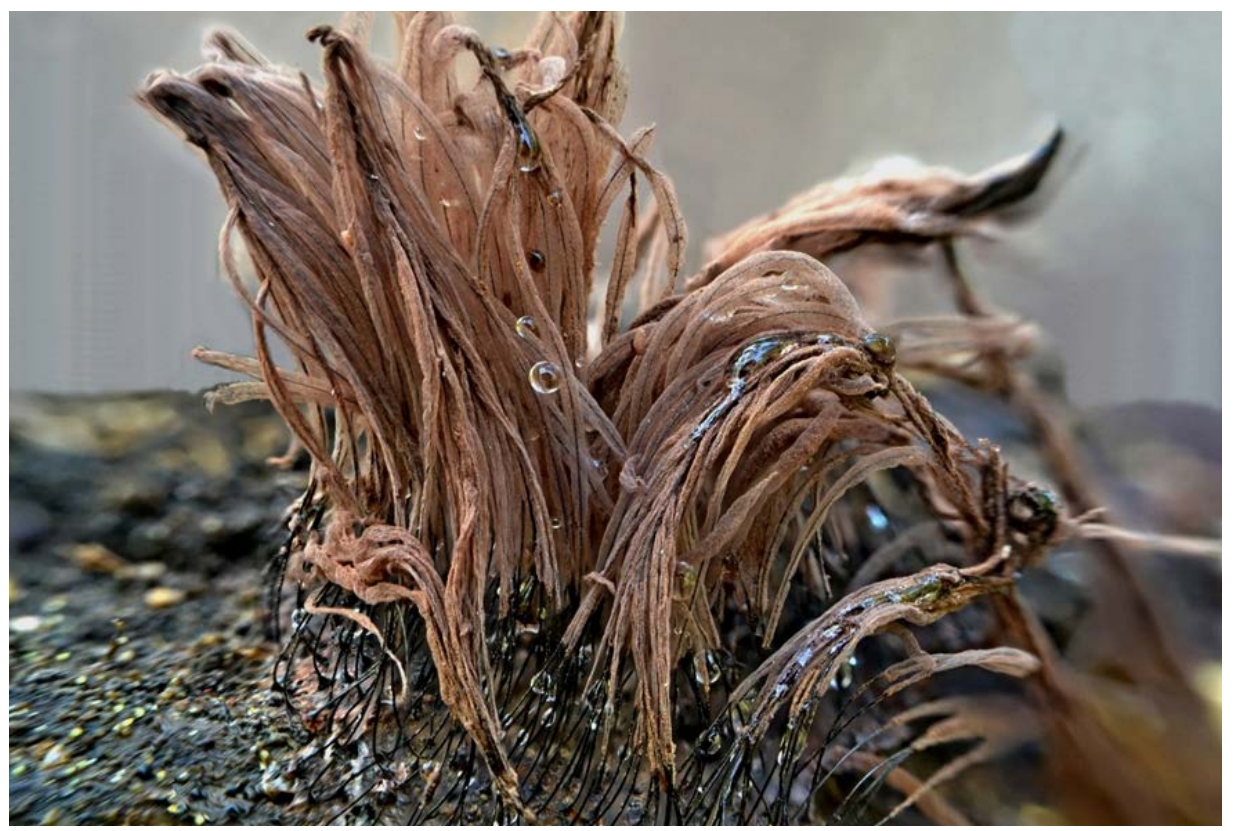

Figura 5. Stemonitis axifera. Fotografía: Emilio J. Salvador.

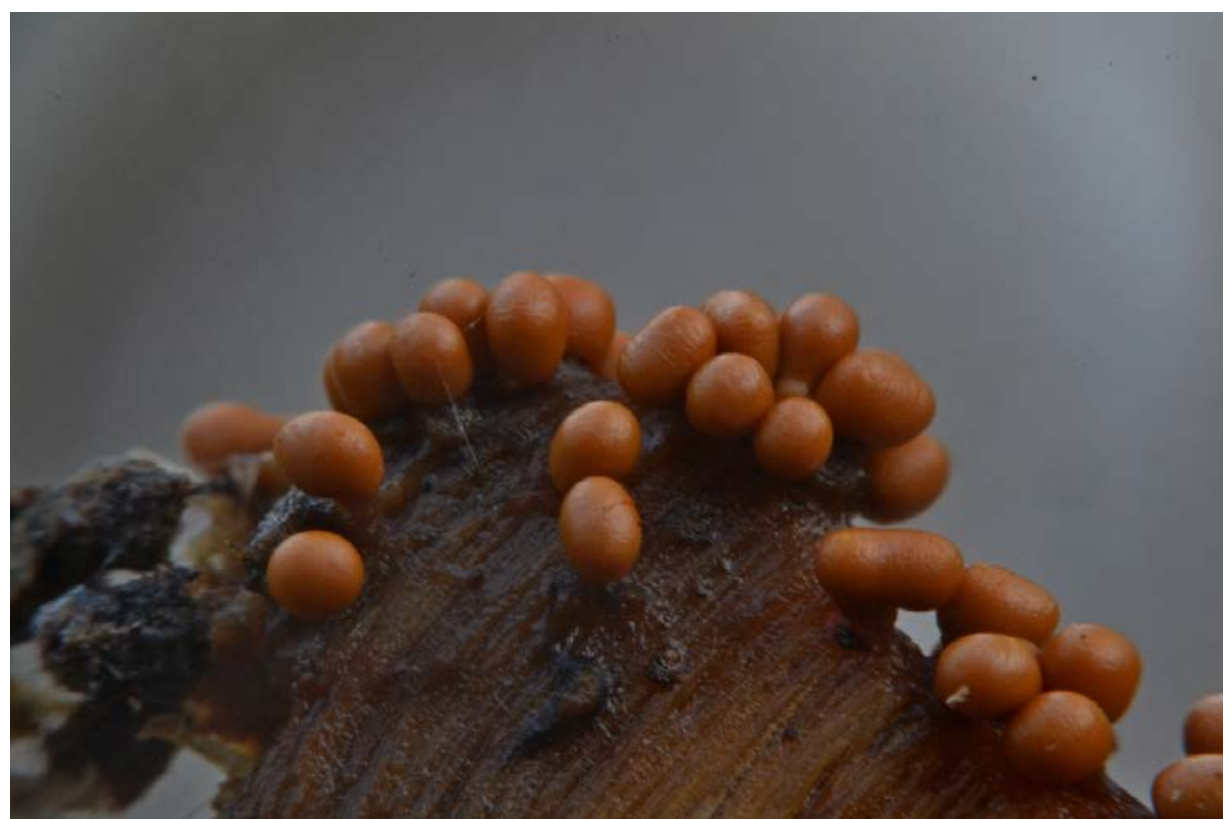

Figura 6. Trichia varia. Fotografía: Emilio J. Salvador. 


\section{FUNGI \\ División ASCOMYCOTA, Subdivisión Pezizomycotina \\ Clase LEOTIOMYCETES}

\section{Orden HELOTIALES}

Familia Arachnopezizaceae

Arachnopeziza aurata Fuckel, 1870

Primera cita para la provincia de este ascomicete con apotecios de unos $0.5 \mathrm{~cm}$, de color blanco a dorado. Sobre madera de planifolios.

Año 2019: 28 de diciembre, Villalgordo del Júcar, sobre madera de Quercus rotundifolia Lam. (Emilio J. Salvador). Figura 7.

Familia Hyaloscyphaceae

Gemmina gemmarum (Boud.) Raitv., 2004

Especie no citada en la provincia. Saprófita sobre diferentes tipos de restos vegetales.

Año 2018: 14 de febrero, El Carrasco (La Roda), sobre madera y amentos de Populus sp. (Emilio J. Salvador). Figura 8.

\section{$\underline{\text { Familia Helotiaceae }}$}

Hymenoscyphus fructigenus (Bull.) Gray, 1821

Según Roldán y Honrubia (1992) es una especie frecuente sobre frutos de Quercus coccifera L. y Q. rotundifolia Lam.

Año 2018: 2 de diciembre, Tarazona de La Mancha, sobre vaina de bellota de encina (Emilio J. Salvador). Figura 9.

Familia Lachnaceae

Incrucipulum ciliare (Schrad.) Baral, 1985

Especie no citada en la provincia. 
Año 2020: 7 de junio, Fuensanta, sobre hoja de Populus alba L. (recolectada por Emilio J. Salvador, determinada por Björn Wergen). Figura 10.

$\underline{\text { Familia Mollisaceae }}$

Tapesia lividofusca (Fr.) Rehm, 1891

Sinónimo Mollisia lividofusca (Fr.) Gillet, 1882

Especie no citada anteriormente en la provincia. Pequeño ascomicete descomponedor de madera muerta.

Año 2020: recogida el 3 de enero en Villalgordo del Júcar sobre rama muerta de Populus alba (Emilio J. Salvador). Figura 11.

\section{Clase SORDARIOMYCETES}

\section{Orden HYPOCREALES}

$\underline{\text { Familia Cordycipitaceae }}$

Hyperdermium caulium (Berk. \& M.A. Curtis) P. Chaverri \& K.T. Hodge, 2008

Sinónimo Terana caulium (Berk. \& M.A. Curtis) Kuntze, 1891

Especie no citada anteriormente en la provincia. Forma costras de un llamativo color azul sobre madera muerta de planifolios.

Año 2020: 3 de enero en Villalgordo del Júcar sobre rama muerta de Quercus rotundifolia Lam. (Emilio J. Salvador). Figura 12.

\section{$\underline{\text { Familia Nectriaceae }}$}

Nectria peziza (Tode) Fr., 1849

Especie no citada en la provincia.

Año 2018: 2 de diciembre, Tarazona de La Mancha, sobre madera de Populus alba L. (Recolectada por Emilio J. Salvador, determinada por Enrique Rubio). Figura 13. 


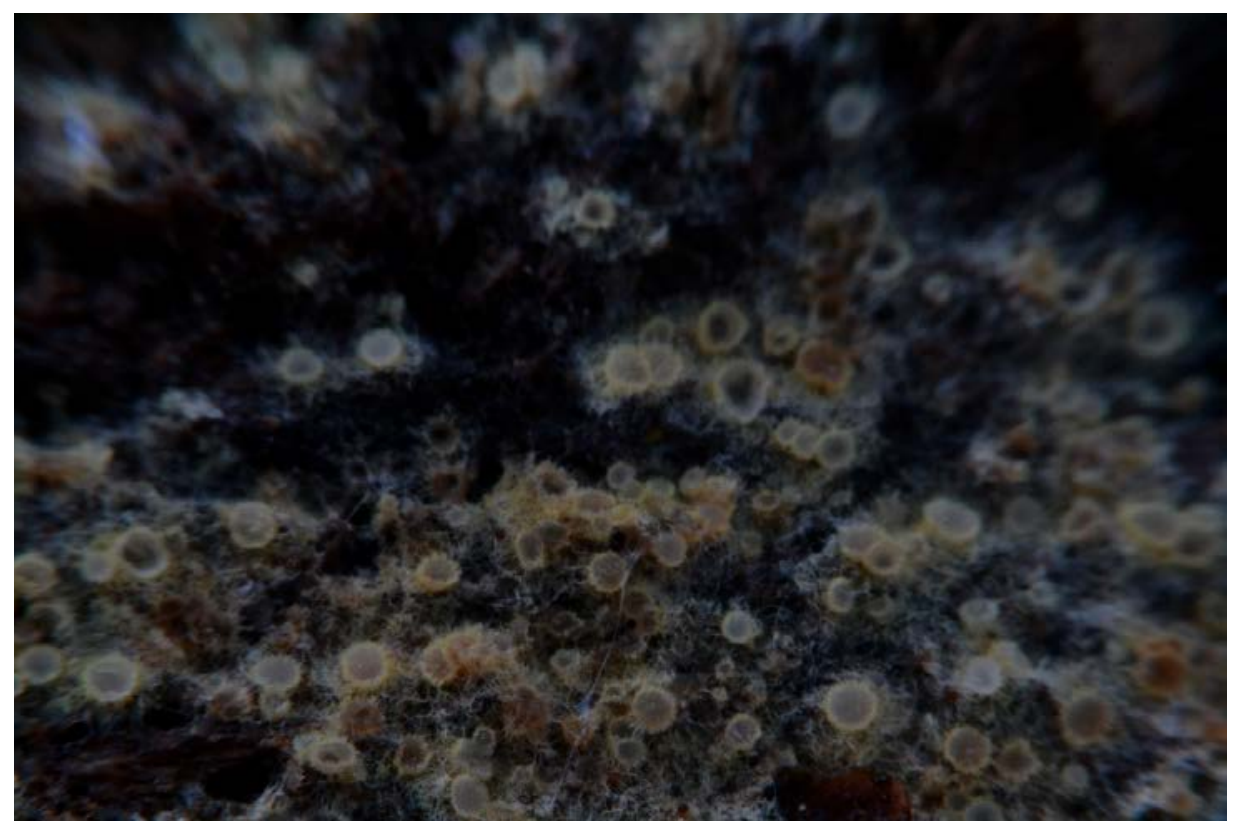

Figura 7. Arachnopeziza aurata. Fotografía: Emilio J. Salvador.

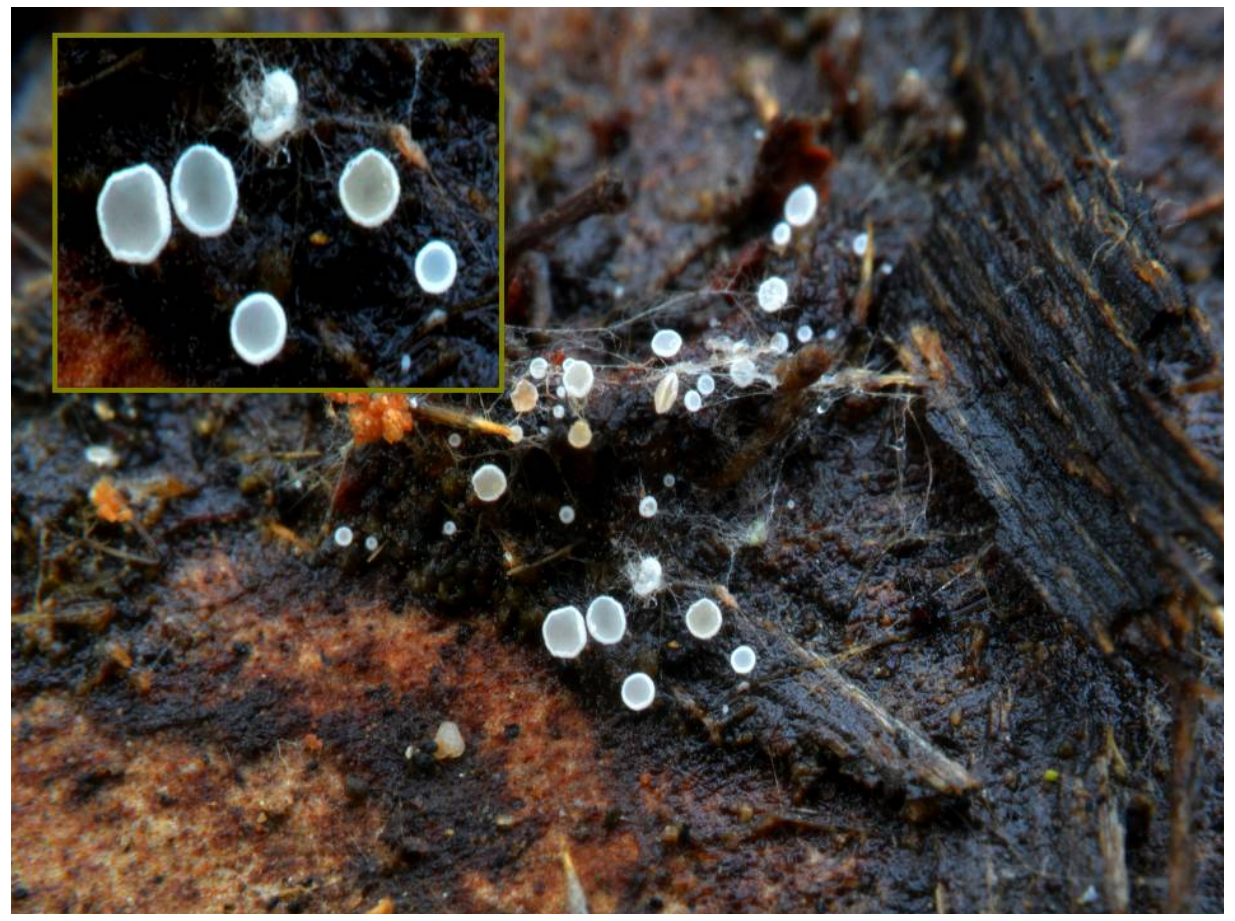

Figura 8. Gemmina gemmarum. Fotografía: Emilio J. Salvador. 


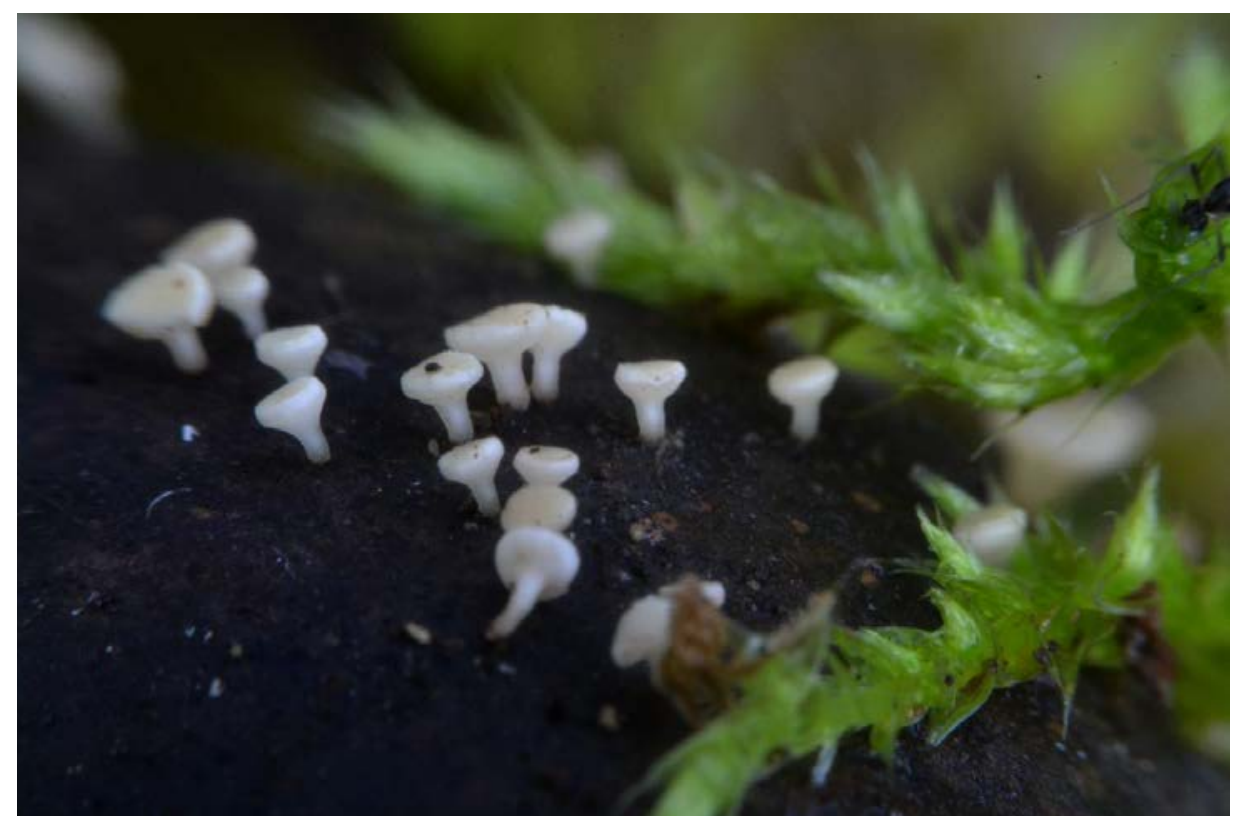

Figura 9. Hymenoscyphus fructigenus. Fotografía: Emilio J. Salvador.

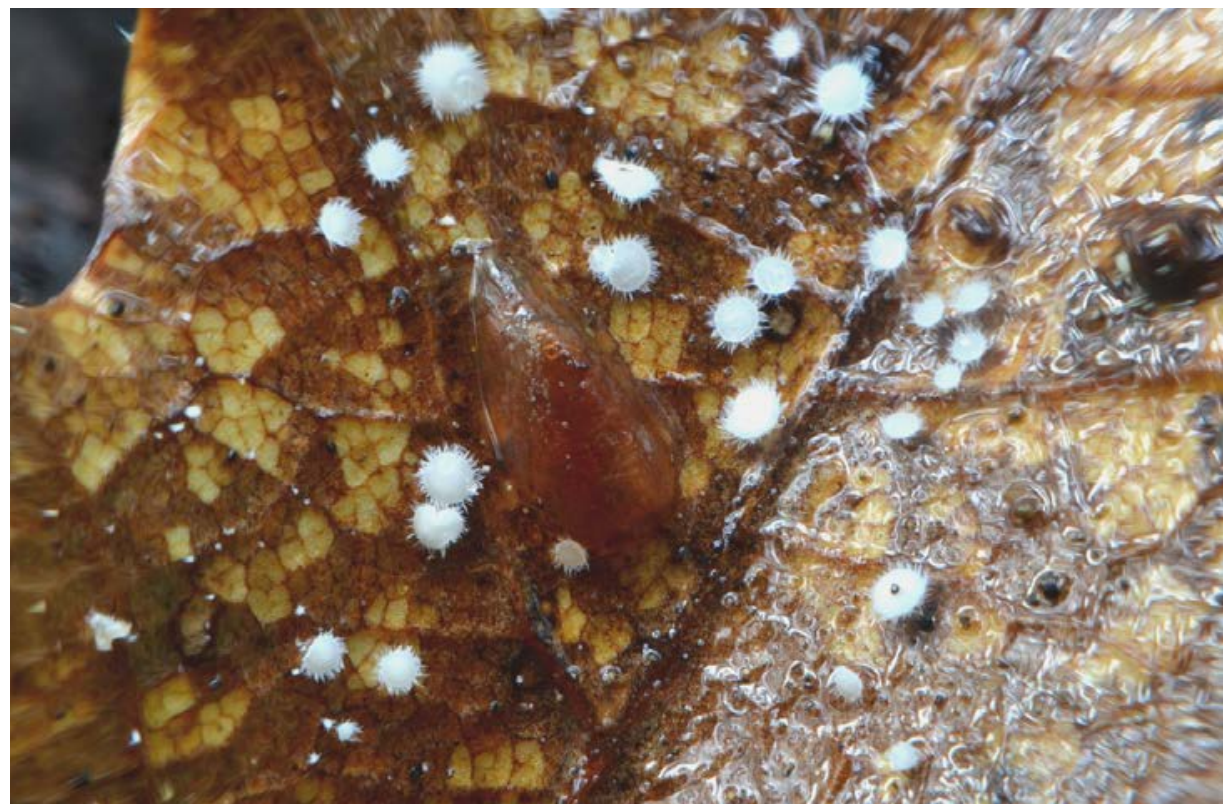

Figura 10. Incrucipulum ciliare. Fotografía: Emilio J. Salvador. 


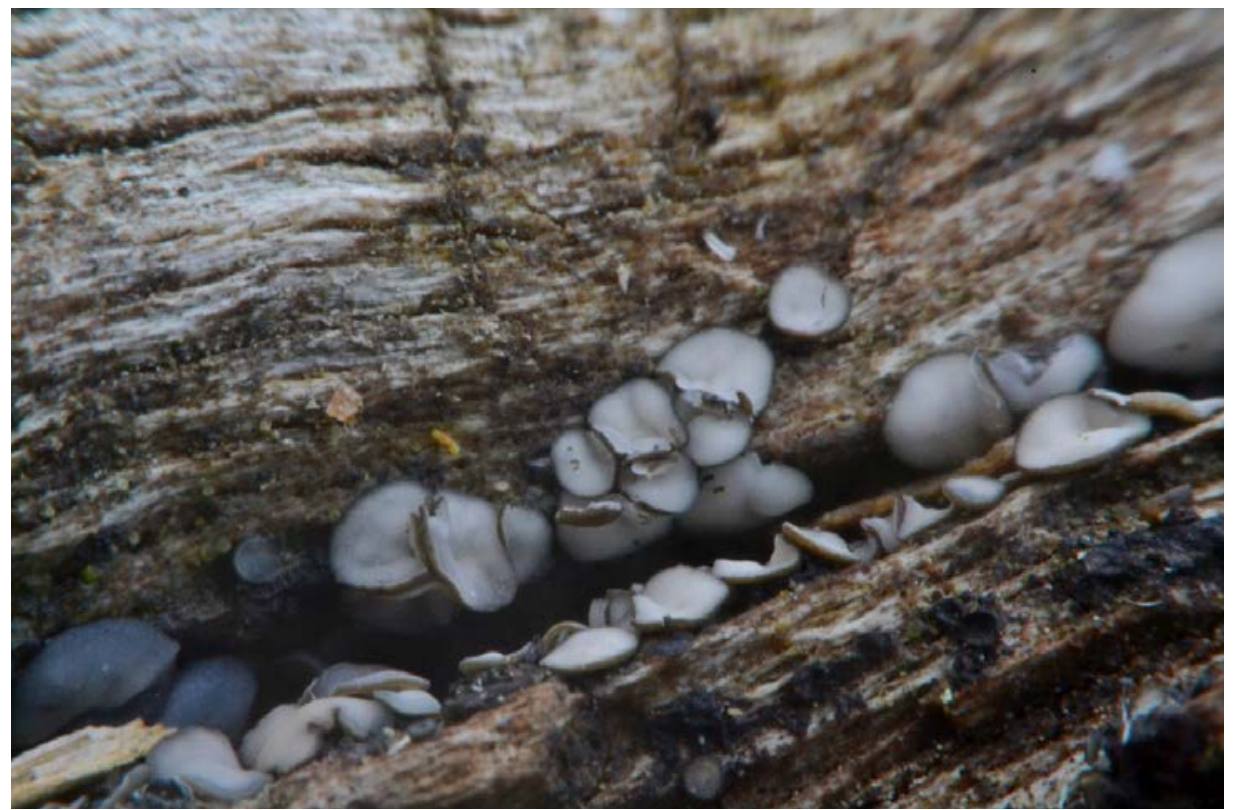

Figura 11. Tapesia lividofusca. Fotografía: Emilio J. Salvador.

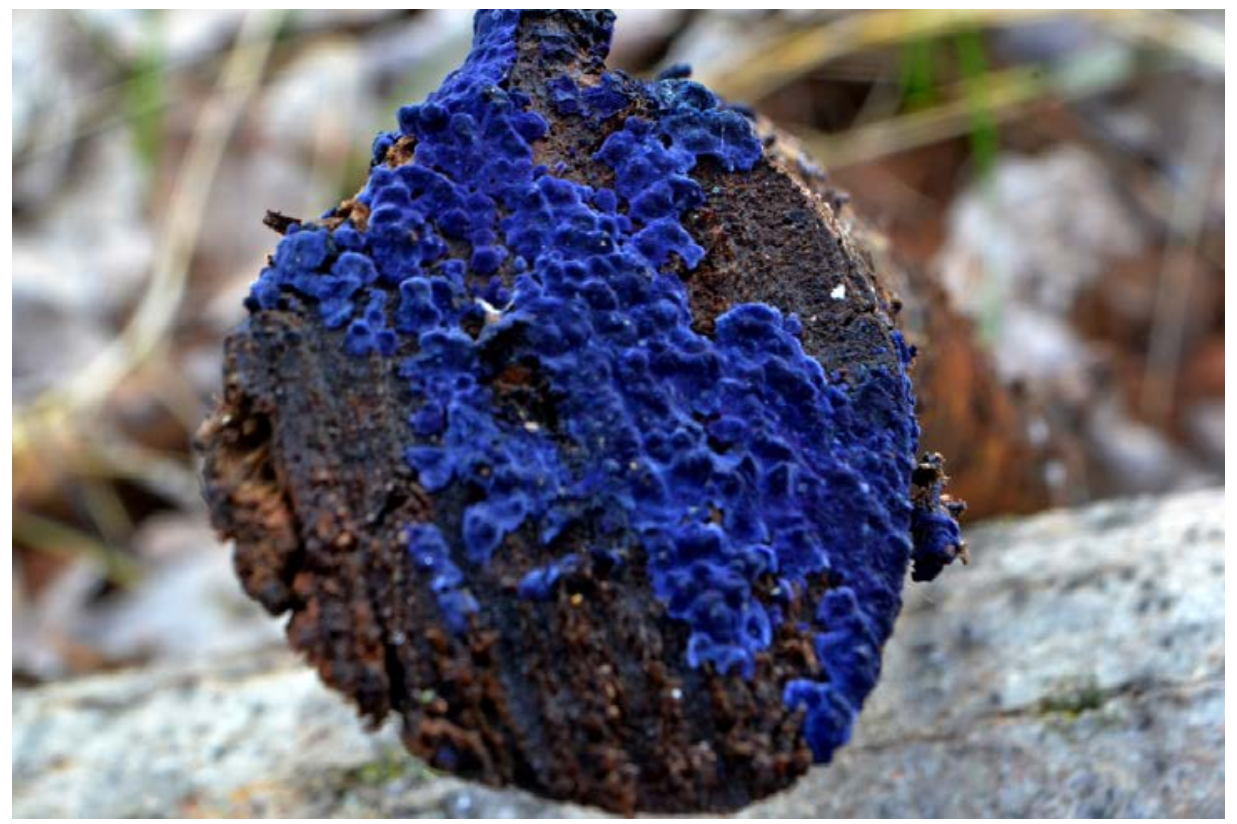

Figura 12. Hyperdermium caulium. Fotografía: Emilio J. Salvador. 


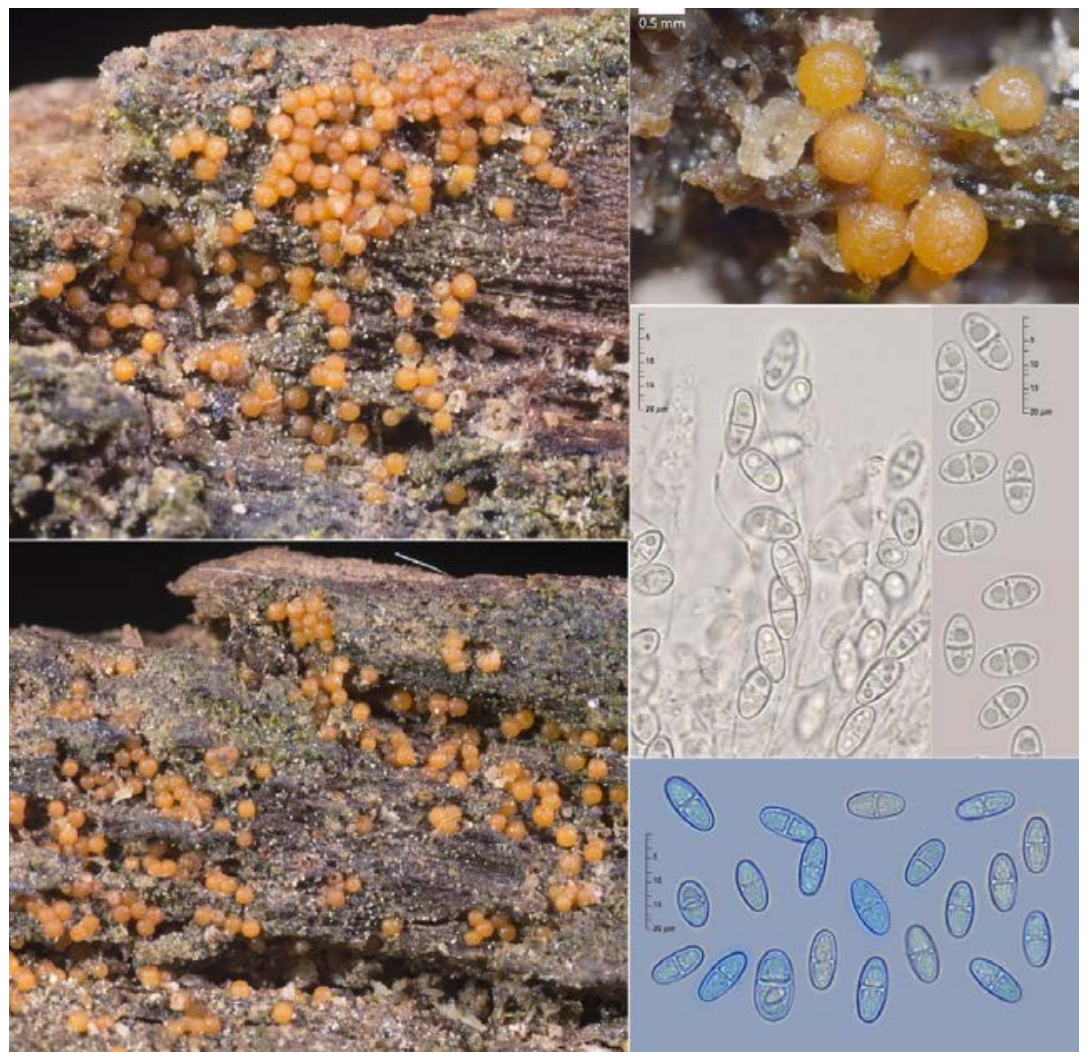

Figura 13. Nectria peziza. Fotografía macro: Emilio J. Salvador. Fotografía micro: Enrique Rubio.

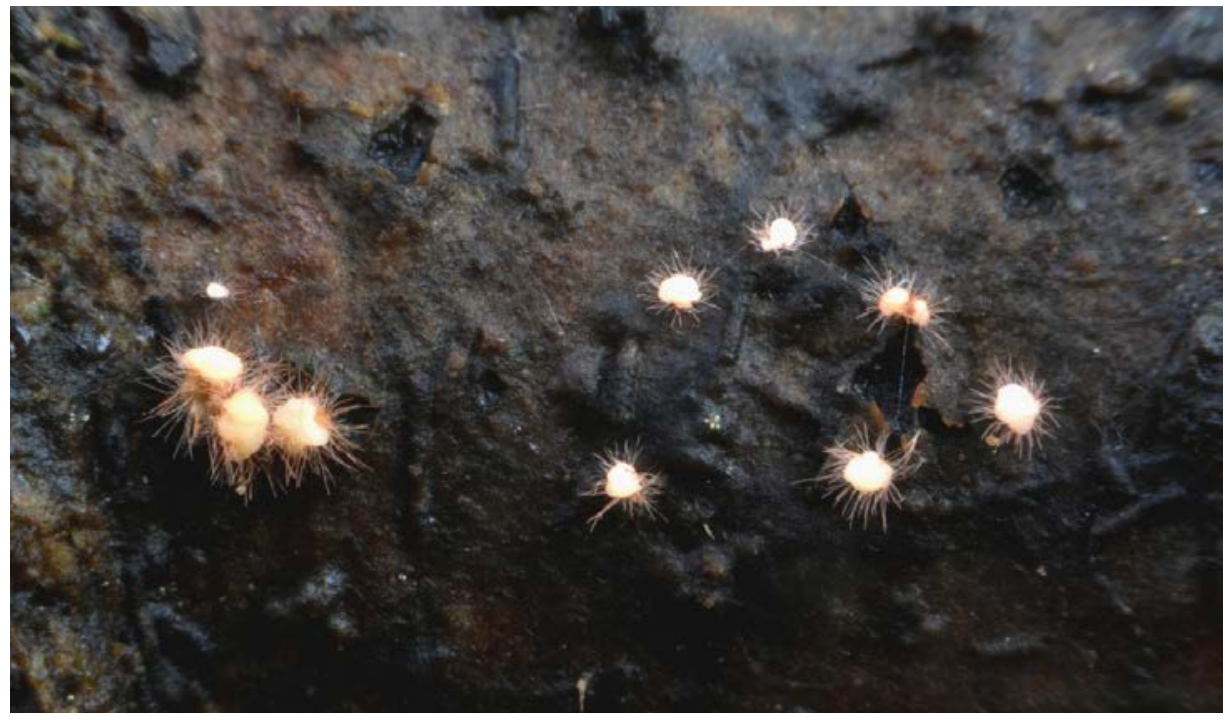

Figura 14. Volutella ciliata. Fotografía: Emilio J. Salvador. 
Volutella ciliata (Alb. \& Schwein.) Fr., 1832

Especie no citada en la provincia. Es la fase asexual de especies del género Pseudonectria Seaver. Sobre restos vegetales en zonas húmedas. Su tamaño muy pequeño hace que pase desapercibida.

Año 2020: 9 de febrero, El Carrasco (La Roda), sobre rama de Populus alba L. (Emilio J. Salvador). Figura 14.

\section{Clase DOTHIDEOMYCETES}

\section{Orden PLEOSPORALES}

$\underline{\text { Familia Leptosphaeriaceae }}$

\section{Leptosphaeria sp.}

Año 2018: 14 de febrero, El Carrasco (La Roda), en tallos de juncos (Emilio J. Salvador). Figura 15.

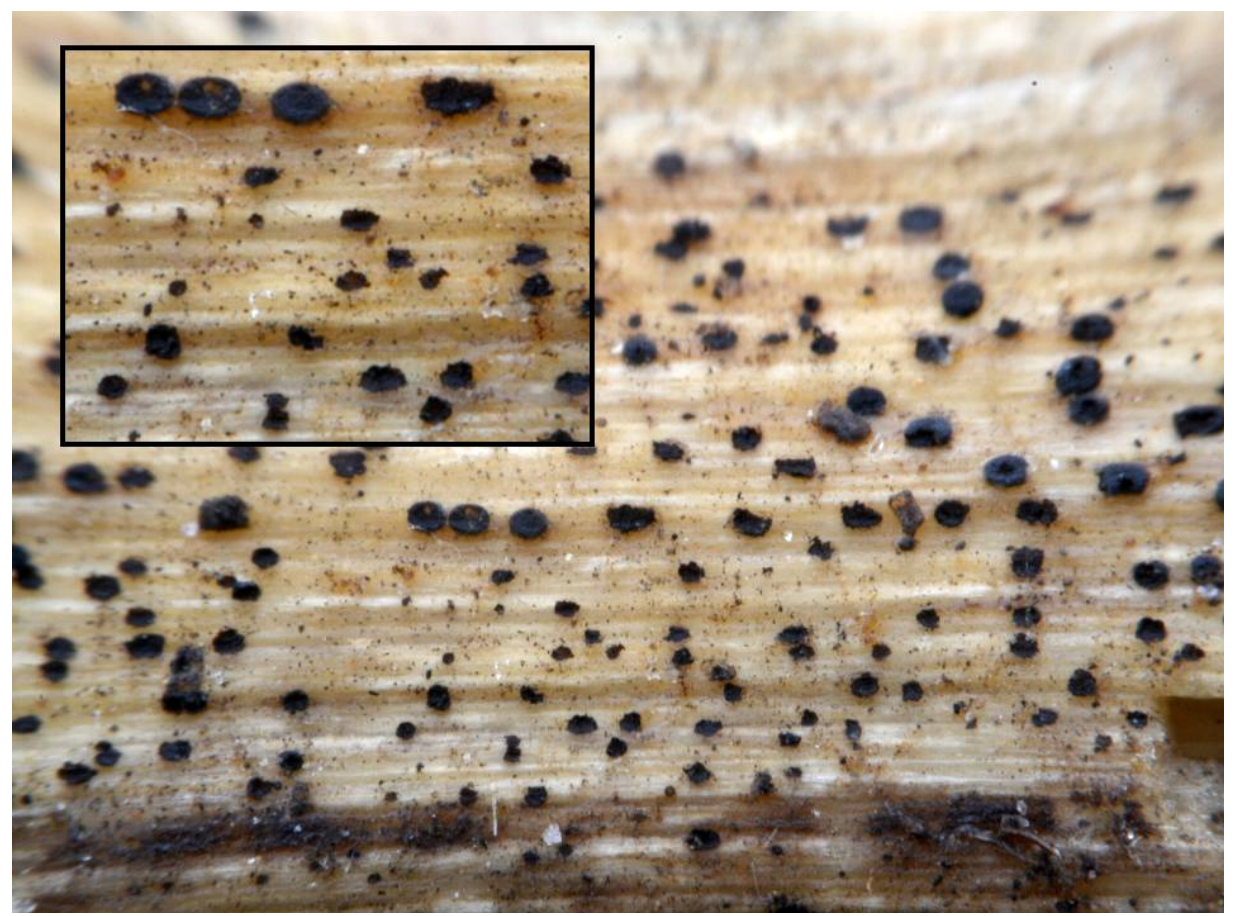

Figura 15. Leptosphaeria sp. Fotografía: Emilio J. Salvador. 


\section{Clase PEZIZOMICETES}

\section{Orden PEZIZALES}

$\underline{\text { Familia Morchellaceae }}$

Morchella dunalii Boud., 1887

Del complejo género Morchella hay pocas referencias bien identificadas en la provincia. Esta es la primera cita de esta especie.

Año 2018: 17 de abril, Villalgordo del Júcar, en bosque mixto de Pinus halepensis y Quercus rotundifolia Lam. (Emilio J. Salvador). Figura 16.

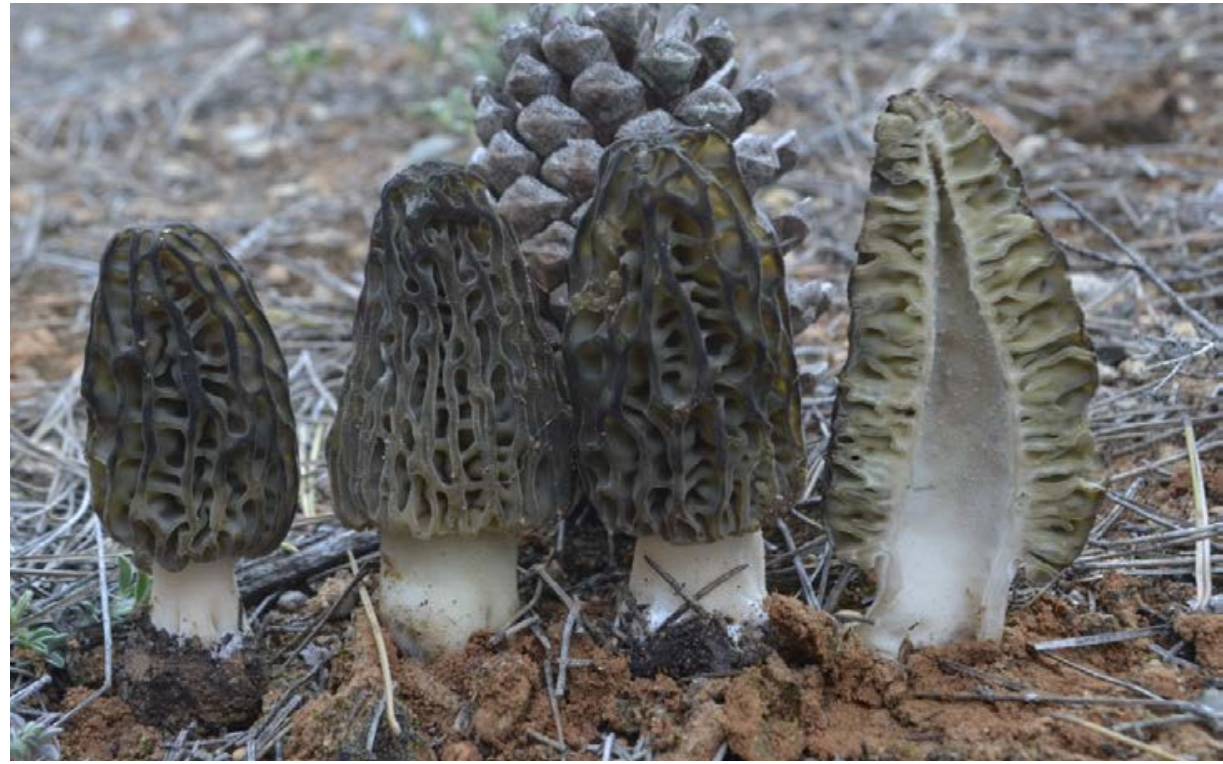

Figura 16. Morchella dunalii. Fotografía: Emilio J. Salvador.

\section{$\underline{\text { Familia Pezizaceae }}$}

Peziza moseri Aviz.-Hersh. \& Nemlich, 1974

Primera cita para la provincia.

Año 2018: 2 de diciembre, Tarazona de La Mancha, en la orilla de un arroyo.

Ecología: borde de un arroyo. (Recolectada por Emilio J. Salvador, determinada por Enrique Rubio). Figuras 17 y 18. 


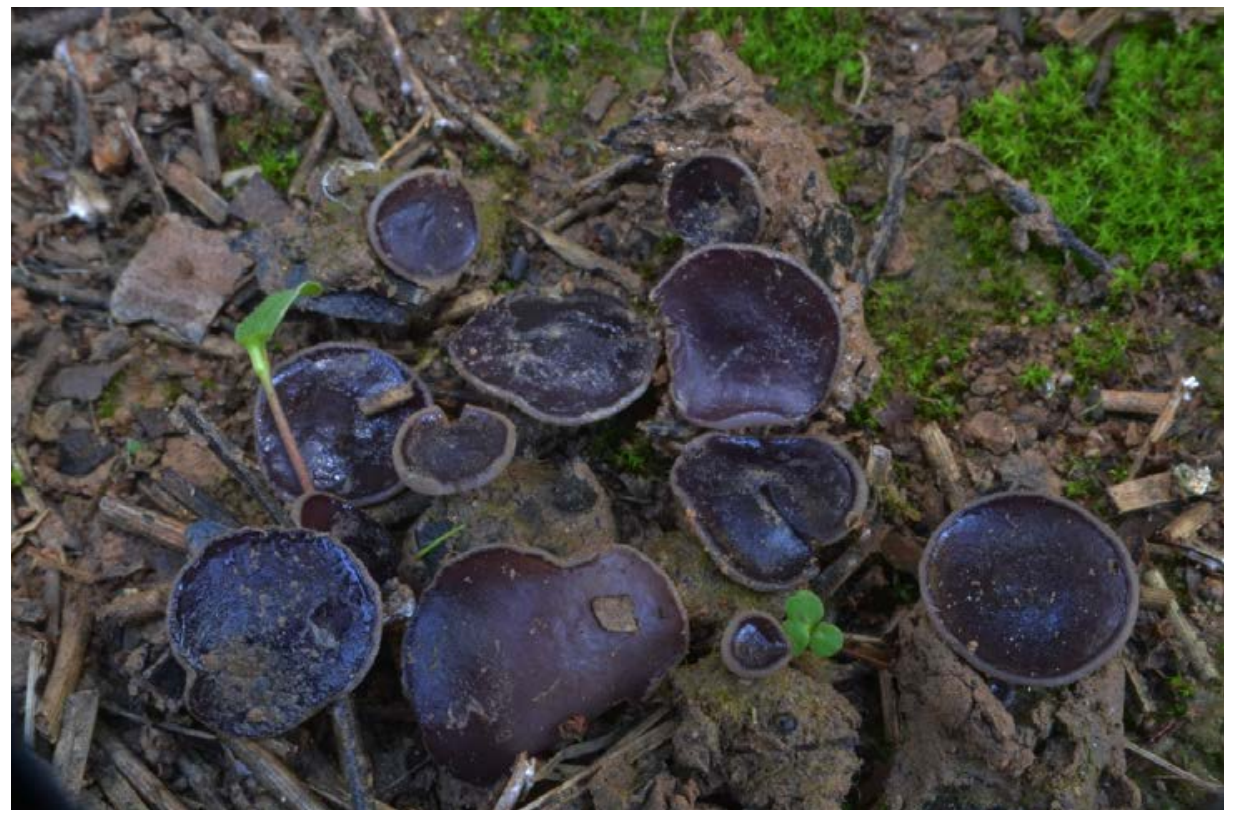

Figura 17. Peziza moseri. Fotografía: Emilio J. Salvador.

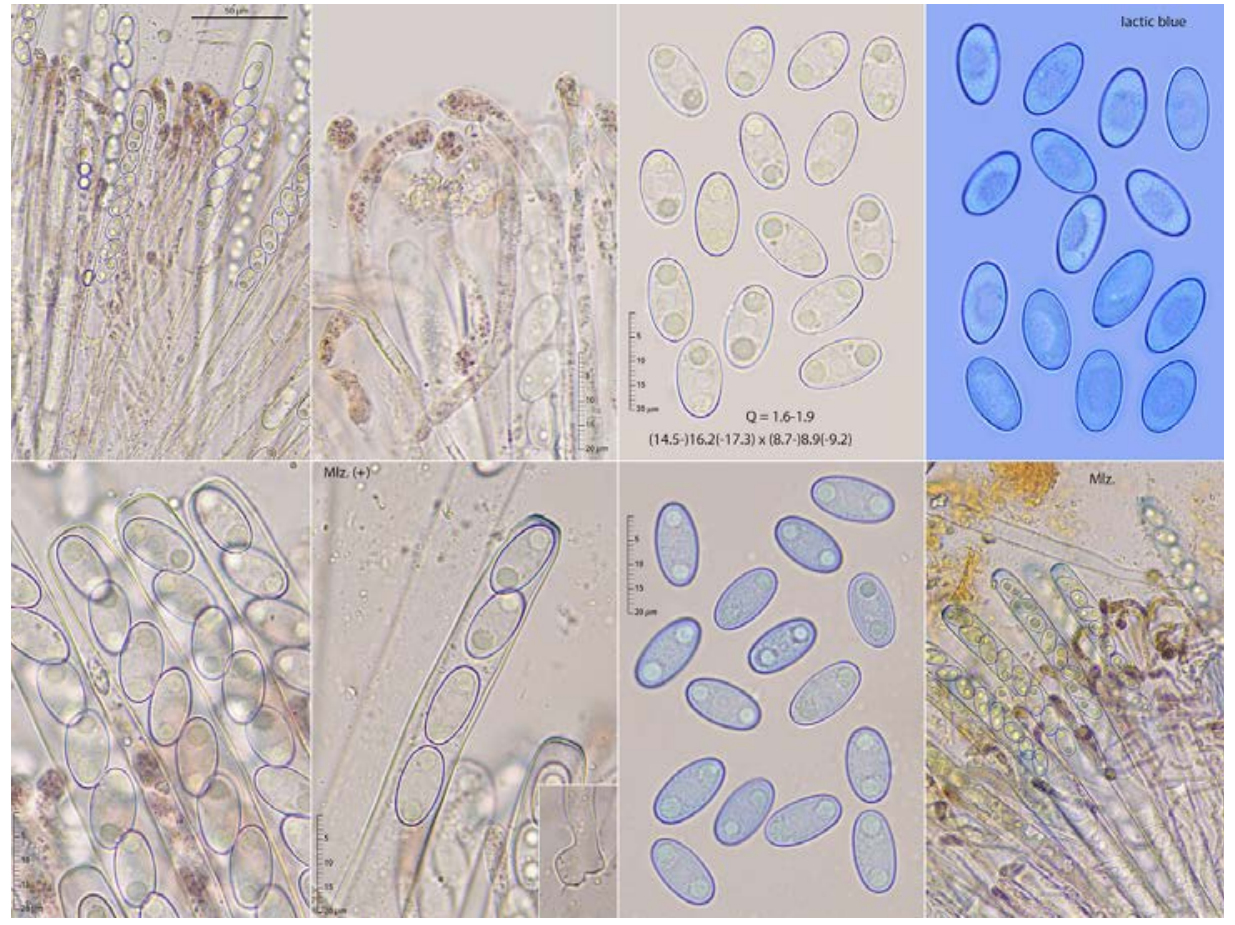

Figura 18. Peziza moseri. Fotografía de microscopía: Enrique Rubio. 


\section{$\underline{\text { Familia Pyronemataceae }}$}

Trichophaeopsis bicuspis (Boud.) Korf \& Erb, 1972

Especie no citada anteriormente en la provincia. Apotecios de hasta 0,5 cm sobre madera muerta.

Año 2020: 3 de enero, Villalgordo del Júcar, sobre madera de Populus alba (Emilio J. Salvador). Figura 19.

\section{División BASIDIOMYCOTA, Subdivisión Agaricomycotina Clase AGARICOMYCETES}

\section{Orden AGARICALES}

\section{Familia Hygrophoraceae}

Arrhenia rickenii (Hora) Watling, 1989

Primera cita provincial.

Año 2019: 28 de diciembre, en Villalgordo del Júcar, creciendo sobre musgo (Emilio J. Salvador). Figura 20.

$\underline{\text { Familia Mycenaceae }}$

Phloeomana speirea (Fr.) Redhead, 2013

Año 2020: 29 de noviembre, en Tarazona de La Mancha (Emilio J. Salvador en Fauna y flora de Albacete).

\section{$\underline{\text { Familia Pleurotaceae }}$}

Hohenbuehelia atrocoerulea (Fr.) Singer, 1951

Especie no citada en la provincia.

Año 2020: 9 de febrero, El Carrasco (La Roda), sobre madera sin identificar (Emilio J. Salvador). Figura 21. 


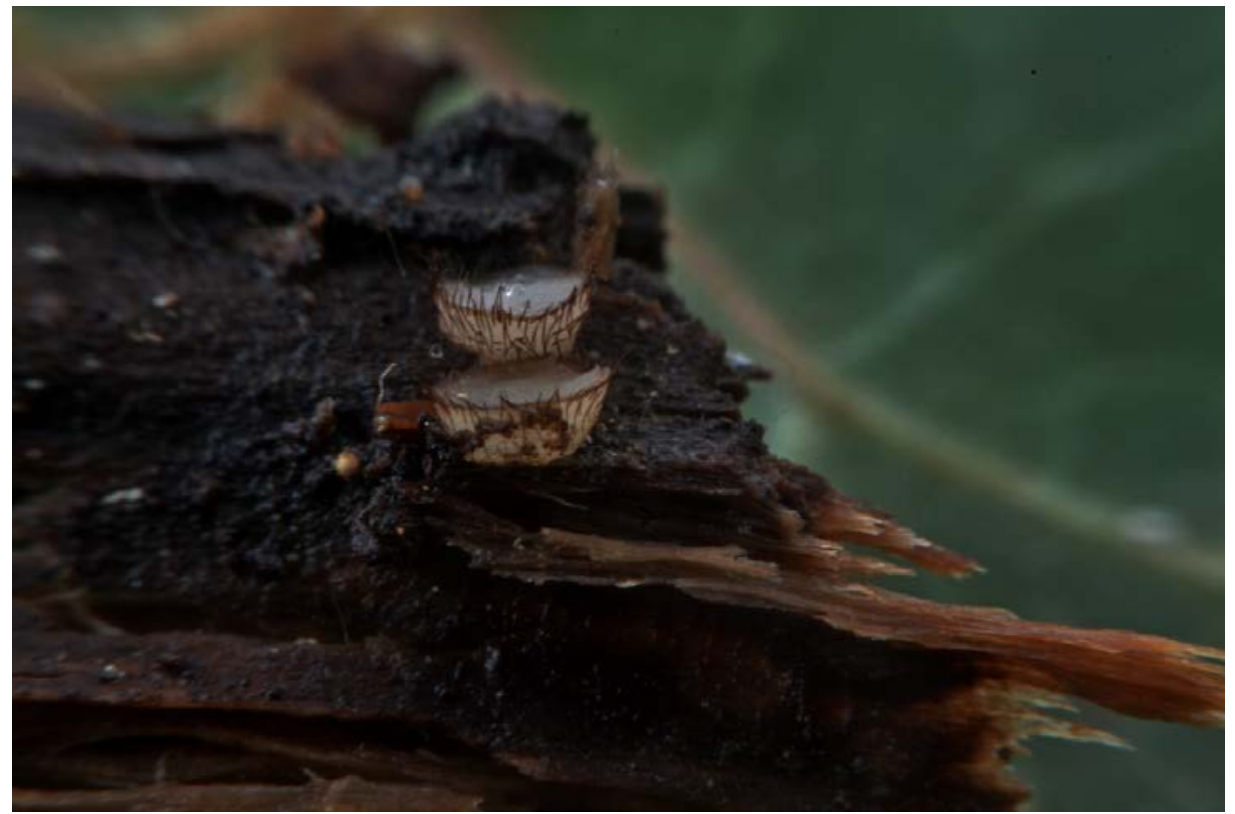

Figura 19. Trichophaeopsis bicuspis. Fotografía: Emilio J. Salvador.

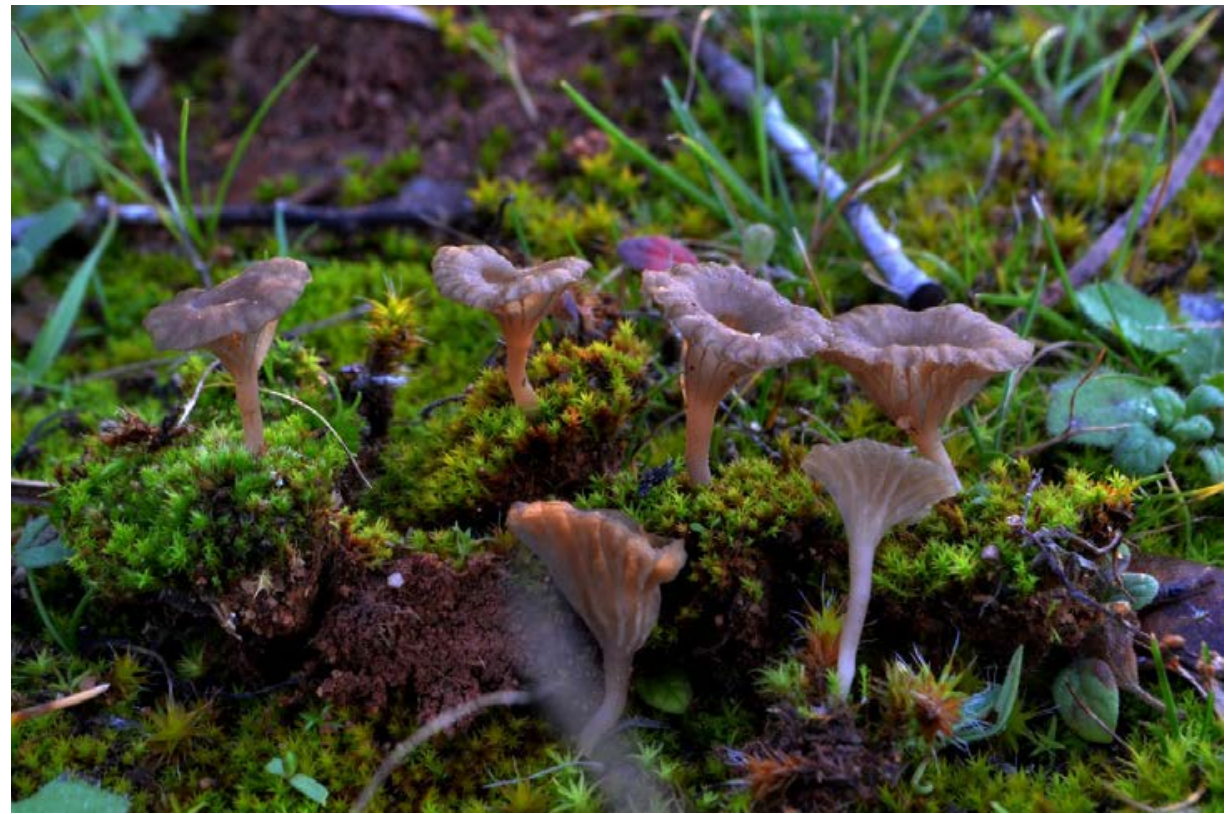

Figura 20. Arrhenia rickenii. Fotografía: Emilio J. Salvador. 
Hohenbuehelia mastrucata (Fr.) Singer, 1951

Especie saprófita que puede aparecer tanto sobre madera muerta de coníferas como de planifolios. Es una especie escasa. En el herbario micológico ALBAMICO hay registradas dos recolecciones en Lezuza y Horno Ciego, Elche de la Sierra.

Año 2018: 2 de diciembre, Tarazona de La Mancha, sobre madera de Populus alba L. (Emilio J. Salvador).

Año 2020: en Fuensanta el 15 de noviembre (Carmelo Pérez en Fauna y flora de Albacete) https:/www.facebook.com/groups/faunayfloradealbacete. 20 de noviembre en Fuensanta (Emilio J. Salvador). Figura 22.

\section{$\underline{\text { Familia Physalacriaceae }}$}

Rhodotus palmatus (Bull.) Maire, 1926

Especie relativamente frecuente, descomponedora de madera de chopos y olmos.

Año 2018: 6 de diciembre en Fuensanta, sobre madera de Populus alba (Emilio J. Salvador).

Año 2020: 15 y 28 de noviembre en Tarazona de La Mancha (Emilio J. Salvador). 21 de diciembre en Tarazona de La Mancha (Antonio Muñoz en Fauna y flora de Albacete) https://www.facebook.com/groups/faunayfloradealbacete. Figura 23.

\section{$\underline{\text { Familia Pluteaceae }}$}

Pluteus aurantiorugosus (Trog) Saccardo, 1896

Especie no citada anteriormente en la provincia.

Año 2020: 21 de noviembre en Las Mariquillas (Albacete) (Carmelo Pérez en Fauna y flora de Albacete) https://www.facebook.com/groups/ faunayfloradealbacete.

\section{$\underline{\text { Familia Psatihyrellaceae }}$}

Psathyrella vinosofulva P.D. Orton, 1960

Primera cita para la provincia.

Año 2020: 15 de noviembre en Fuensanta (Pablo López Aracil en Fauna y flora de Albacete) https:/www.facebook.com/groups/faunayfloradealbacete. 


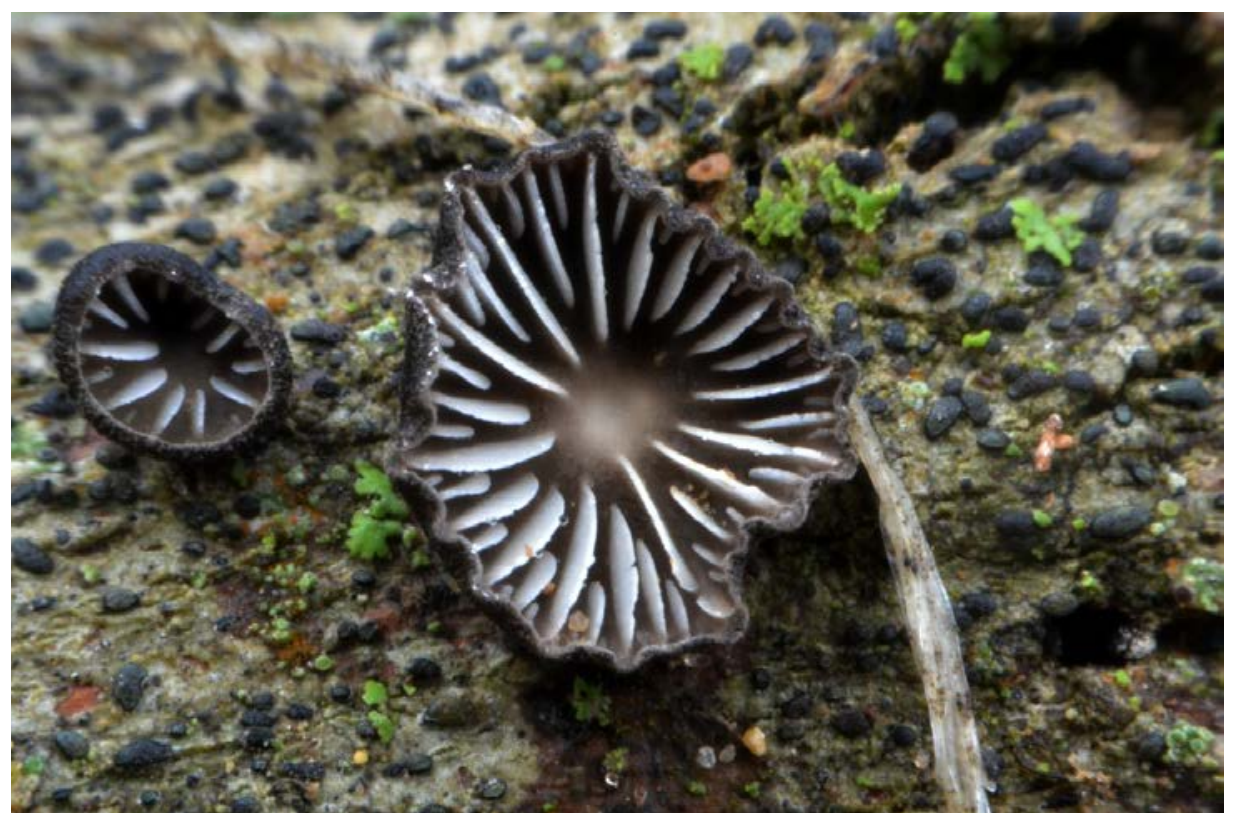

Figura 21. Hohenbuehelia atrocaerulea. Fotografía: Emilio J. Salvador.

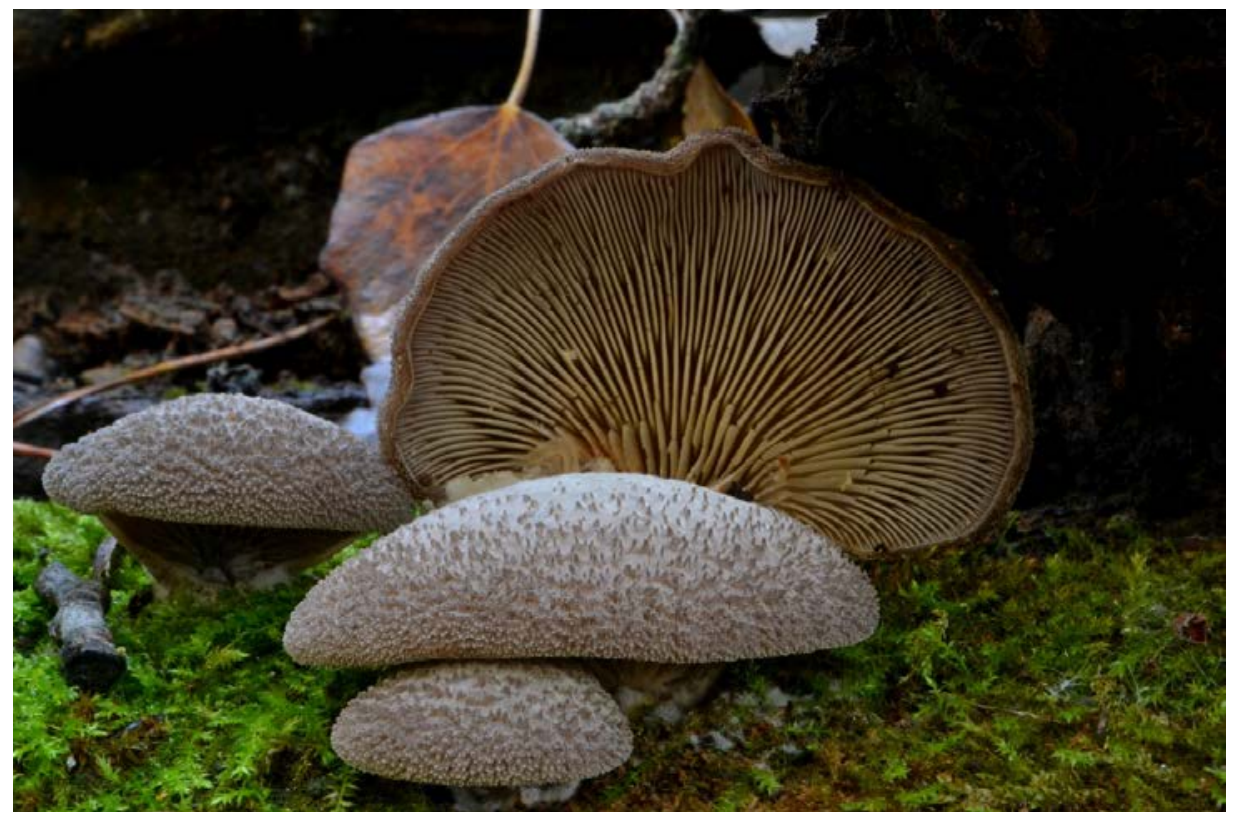

Figura 22. Hohenbuehelia mastrucata. Fotografía: Emilio J. Salvador. 


\section{$\underline{\text { Familia Schizophyllaceae }}$}

Schizophyllum amplum (Lév.) Nakasone, 1996

Sinónimo Auriculariopsis ampla (Lév.) Maire, 1902

Especie poco citada en la provincia, aunque probablemente pase desapercibida por su tamaño y ecología, descomponedora de ramitas muertas de chopo.

Año 2109: 26 de enero, sobre rama de Populus alba L. en Villalgordo del Júcar (Emilio J. Salvador). Figura 24.

Familia Tubariaceae

Phaeomarasmius erinaceus (Fries) Scherffel ex Romagnesi, 1937

Especie no citada anteriormente en la provincia.

Año 2020: 29 de noviembre, en Fuensanta (Emilio J. Salvador en Fauna y flora de Albacete) https://www.facebook.com/groups/faunayfloradealbacete.

Phaeomarasmius rimulincola (Lasch ex Rabenhorst) Scherffel, 1914 Año 2020: 29 de noviembre, en Tarazona de La Mancha (Emilio J. Salvador en Fauna y flora de Albacete) https://www.facebook.com/groups/ faunayfloradealbacete.

\section{Orden AURICULARIALES}

\section{Familia Exidiaceae}

Hirneolina leucophaea (Bresadola) Bresadola, 1905

Sinónimo Exidiopsis leucophaea (Bres.) K. Wells, 1962

Especie no citada anteriormente en la provincia.

Año 2020: Tarazona de La Mancha, 29 de noviembre (Emilio J. Salvador en Fauna y flora de Albacete) https://www.facebook.com/groups/faunayfloradealbacete.

\section{Orden POLYPORALES}

$\underline{\text { Familia Polyporaceae }}$ 


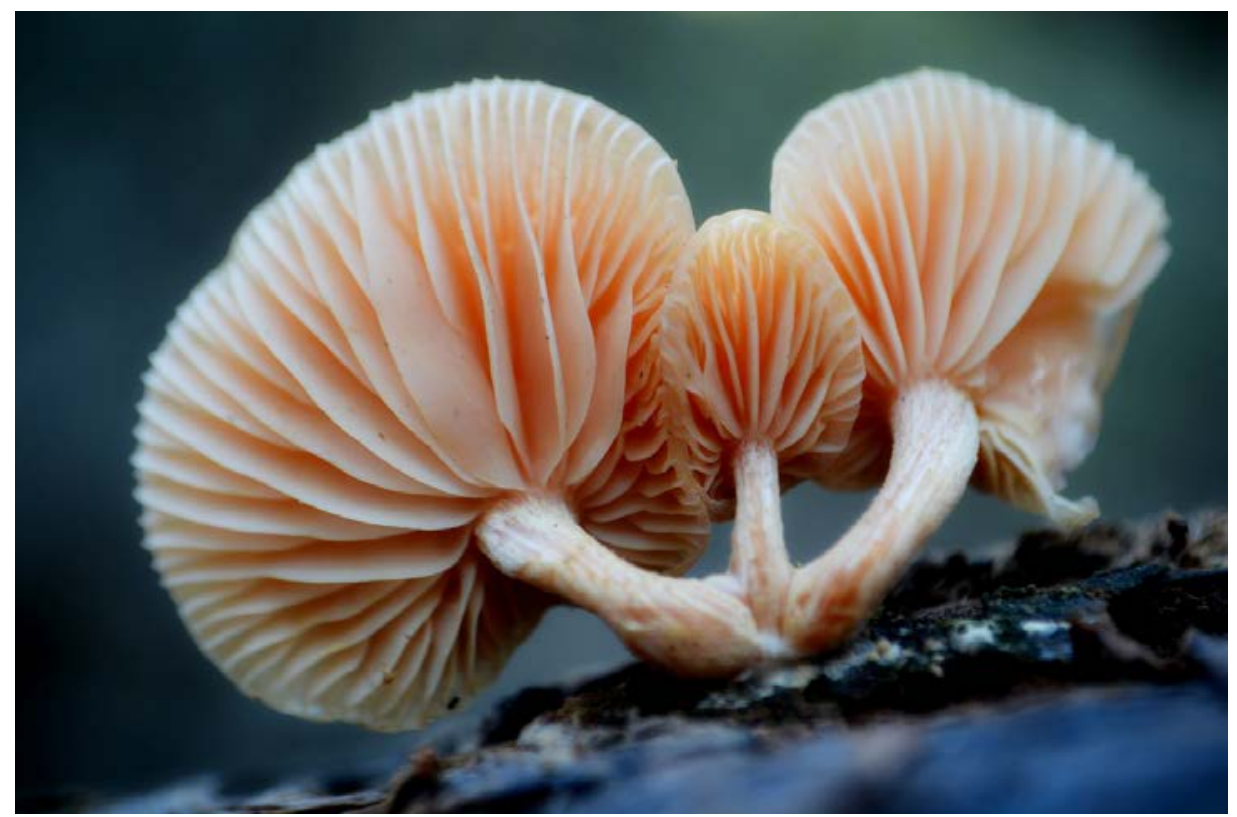

Figura 23. Rhodotus palmatus. Fotografía: Emilio J. Salvador.

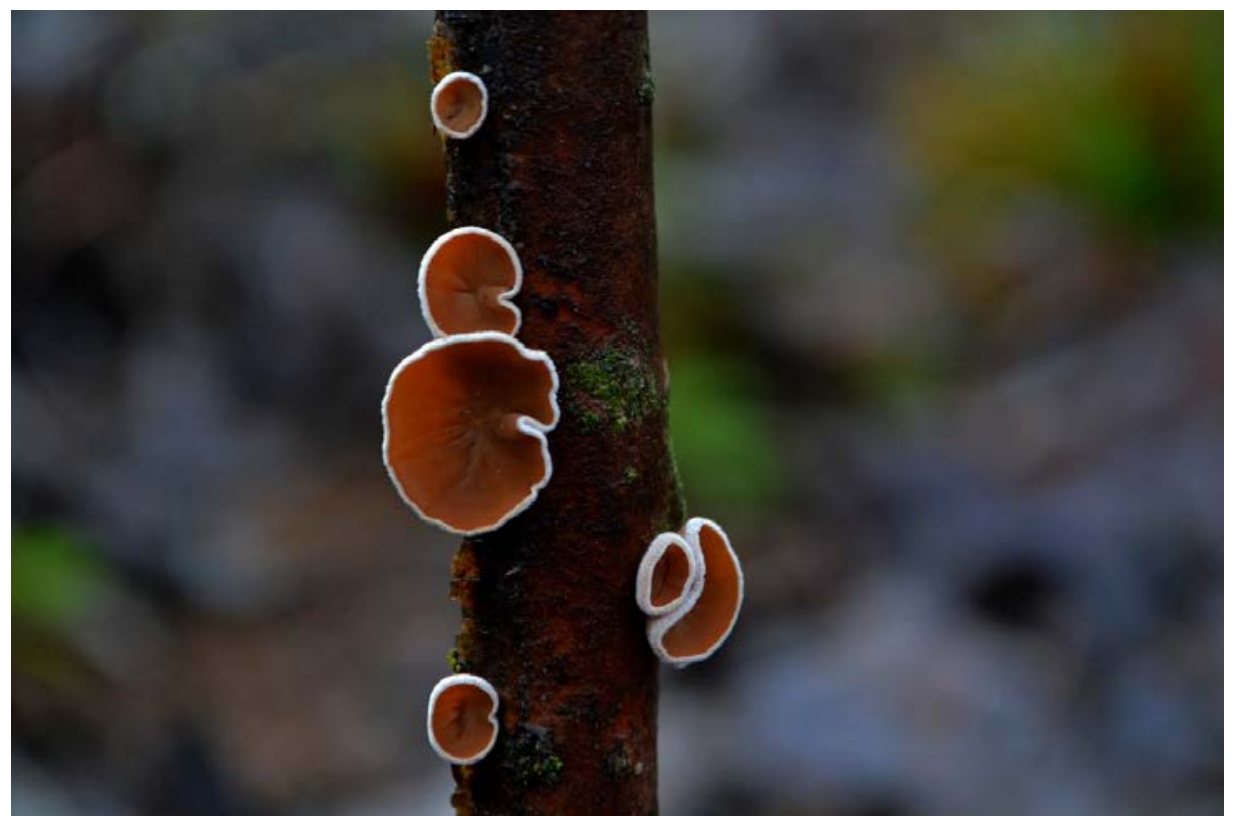

Figura 24. Schizophyllum amplum. Fotografía: Emilio J. Salvador. 
Ganoderma resinaceum Boudier, 1889

Especie no citada anteriormente para la provincia.

Año 2020: 20 de diciembre, en Tarazona de La Mancha (Antonio Muñoz en Fauna y flora de Albacete) https://www.facebook.com/groups/faunayfloradealbacete.

$\underline{\text { Familia Phanerochaetaceae }}$

Hapalopilus rutilans (Perssoon) Murrill, 1904

Especie no citada anteriormente para la provincia.

Año 2020: 21 de noviembre, en Las Mariquillas (Albacete) (Carmelo Pérez en Fauna y flora de Albacete) https://www.facebook.com/groups/ faunayfloradealbacete.

\section{Orden RUSSULALES}

$\underline{\text { Familia Hericiaceae }}$

Hericium clathroides (Pallas) Persoon, 1797

Especie sin citas anteriores en la provincia.

Año 2020: 21 de diciembre, en Bienservida. (Carmelo Pérez en Fauna y flora de Albacete) https:/www.facebook.com/groups/faunayfloradealbacete.

\section{Clase DACRYMYCETES}

\section{Orden DACRYMYCETALES}

\section{$\underline{\text { Familia Dacrymycetaceae }}$}

Calocera cornea (Batsch) Fries, 1827

Especie no citada anteriormente en la provincia. Probablemente su pequeño tamaño y textura gelatinosa, poco persistente, haya hecho que pase desapercibida.

Año 2020: 15 de noviembre, en Tarazona de La Mancha (Pablo López en Fauna y flora de Albacete) https:/www.facebook.com/groups/faunayfloradealbacete. 


\section{ANIMALIA \\ Phylum Annelida \\ Clase OLIGOCHETA}

\section{Orden OPISTOPOHORA}

$\underline{\text { Familia Lumbricidae }}$

Zophoscolex albacetensis Pérez-Onteniente y Rodríguez-Babío, 2010 Especie nueva, descrita por Pérez-Onteniente y Rodríguez-Babío (2010) a partir de los resultados obtenidos en un trabajo subvencionado por el Instituto de Estudios Albacetenses Don Juan Manuel durante el otoñoinvierno 2006-07. Los ejemplares que sirvieron para la descripción se recolectaron en dos localidades: puerto de El Arenal (Riópar) y Las Hoyas (Molinicos).

\section{Phylum Arthropoda Clase INSECTA}

\section{Orden ODONATA}

$\underline{\text { Familia Lestidae }}$

Lestes macrostigma (Eversmann, 1836)

Especie no encontrada anteriormente en la provincia. Díaz-Martínez et al. (2018) recogen 10 citas, todas ellas en el año 2018, en 4 localidades diferentes: Laguna de Pétrola, Hoya de la Yerba (Corral Rubio), Salinas de Pinilla (Alcaraz-El Bonillo) y balsa de Chinchilla de Montearagón.

Lestes virens virens (Charpentier, 1825)

Especie sin citas previas. Díaz-Martínez et al. (2018) recogen 8 citas, todas ellas en el año 2018, y en 4 localidades diferentes: laguna de Pétrola, Hoya de la Yerba (Corral Rubio), Salinas de Pinilla (Alcaraz-El Bonillo) y Navalcudia-Navajoluengo (El Bonillo). 
Chalcolestes viridis (Vander Linden, 1825)

Especie con pocas citas en la provincia. Además de la cita que se indica, también es citada, sin especificar fechas ni individuos, por Grand (2013) en varias localidades del tramo de río Cabriel fronterizo entre las provincias de Valencia y Albacete, como primera cita para el entorno de dicho río.

Año 2008: 2 machos y una hembra el 23 de julio en Villapalacios, puente sobre el río Guadalmena (30S.WH.28.71). Publicada en Salamanca Ocaña et al. (2013) como especie nueva para la provincia.

$\underline{\text { Familia Platycnemididae }}$

Platycnemis acutipennis Selys, 1841

Especie endémica de la península ibérica y gran parte de Francia. Citada en la mayoría de las provincias españolas. Se aporta aquí la primera cita publicada para Albacete.

Año 2019: una hembra y un macho el día 26 de junio en la vegetación perilagunar, Laguna de San Pedro (Ossa de Montiel). Publicada por Evangelio Pinach y Torres López (2020).

$\underline{\text { Familia Coenagrionidae }}$

Ceriagrion tenellum (Villers, 1798)

Año 2008: un macho el 11 de agosto en el embalse de Arroyo Frío (Cotillas). Publicada en Cano Villegas et al. (2014) como especie nueva para la provincia.

Coenagrion caerulescens (Fonscolombe, 1838)

Especie con pocas citas en la provincia. Además de la cita que se indica, también es citada, sin especificar fechas ni individuos, por Grand (2013) en varias localidades del tramo de río Cabriel fronterizo entre las provincias de Valencia y Albacete, como primera cita para el entorno de dicho río.

Año 2008: un macho, una hembra y presencia de larvas el 25 de julio en el cortijo Nemesio (Villapalacios). Publicada en Salamanca Ocaña et al. (2013) como especie nueva para la provincia. 
Coenagrion mercuriale (Charp., 1840)

Especie incluida en el anexo 2 de la directiva Habitats. Se cita, sin especificar fechas ni individuos, por Grand (2013) en varias localidades del tramo de río Cabriel fronterizo entre las provincias de Valencia y Albacete.

\section{Erythromma lindenii (Selys, 1840)}

Especie con pocas citas en la provincia. Se cita, sin especificar fechas ni individuos, por Grand (2013) en varias localidades del tramo de río Cabriel fronterizo entre las provincias de Valencia y Albacete, como primera cita para el entorno de dicho río.

\section{Erythromma viridulum (Charpentier, 1840)}

Especie no encontrada anteriormente en la provincia. Díaz-Martínez et al. (2018) recogen 6 citas, en el año 2017 en Cañada del Salobral (Peñas de San Pedro) y presa de Tavizna (Hellín); en el año 2018 en Salinas de Pinilla (Alcaraz-El Bonillo) y Hoya de la Yerba (Corral Rubio).

\section{Pyrrhosoma nymphula (Sulzer, 1776)}

Año 2008: presencia de larvas el 12 de marzo en el río Zapateros (Vianos) (30S.WH.43.67). Publicada en Salamanca Ocaña et al. (2013) como especie nueva para la provincia.

$\underline{\text { Familia Aeshnidae }}$

Aeshna cyanea (Müller, 1764)

Año 2012: tres machos y una hembra el 11 de agosto en el embalse de Arroyo Frío (Cotillas). Publicada en Cano Villegas et al. (2014) como especie nueva para la provincia.

Aeshna mixta Latreille, 1805

Especie con pocas citas en la provincia. Se cita, sin especificar fechas ni individuos, por Grand (2013) en varias localidades del tramo de río Cabriel fronterizo entre las provincias de Valencia y Albacete, como primera cita para el entorno de dicho río. 
Anax ephippiger (Burmeister, 1839)

Especie de gran tamaño, originaria de zonas tropicales de África y Asia, de costumbres migratorias, por lo que aparece regularmente en zonas templadas y mediterráneas de Europa. Con escasas observaciones en CastillaLa Mancha.

Año 2017: macho adulto el 17 de abril en la laguna de Pétrola. Fotografiada por Fernando Camuñas. Publicada en Camuñas Mohinelo y Álvarez Fidalgo (2018) como primera cita para la provincia.

\section{Familia Gomphidae}

\section{Onychogomphus costae Selys, 1885}

Especie con pocas citas en la provincia, clasificada como EN (En Peligro) por la Unión Internacional para la Conservación de la Naturaleza. Se cita, sin especificar fechas ni individuos, por Grand (2013) en varias localidades del tramo de río Cabriel fronterizo entre las provincias de Valencia y Albacete, como primera cita para el entorno de dicho río.

\section{$\underline{\text { Familia Libellulidae }}$}

\section{Orthetrum trinacria (Selys, 1841)}

Especie no encontrada anteriormente en la provincia. Díaz-Martínez et al. (2018) recogen dos citas, ambas en la misma localidad, el embalse Rambla del Riego (Hellín): 24 de mayo de $\underline{2016}$ y 1 de julio de 2018.

\section{Sympetrum sanguineum (Müller, 1764)}

Especie no encontrada anteriormente en la provincia. Díaz-Martínez et al. (2018) recogen una cita el 16 de septiembre de 2017 en la laguna de Mojón Blanco (Corral Rubio).

\section{Sympetrum sinaiticum Dumont, 1977}

Álvarez Fidalgo et al. (2018) recogen las primeras citas para esta especie en la provincia.

Años 2014-2017: durante estos años la especie se registra con regularidad en una piscina y balsa de riego de una finca particular en Casas del 
Campo (Villarrobledo), en un entorno agrícola. Observaciones de Pablo Sánchez Fernández publicadas en Álvarez Fidalgo et al. (2018).

Año 2017: una hembra fotografiada el 31 de julio en La Resinera (Cotillas) (30SWH45) (Miguel Domenech). Cita publicada en Álvarez Fidalgo et al. (2018).

Sympetrum striolatum (Charpentier, 1840)

Año 2008: un macho el 24 de julio en el río Salobre (Vianos) (30S. WH.35.74). Publicada en Salamanca Ocaña et al. (2013) como especie nueva para la provincia.

Zygonyx torridus (Kirby, 1889)

Clasificada como EN (en peligro) por la Unión Internacional para la Conservación de la Naturaleza. Se cita, sin especificar fechas ni individuos, por Grand (2013) en varias localidades del tramo de río Cabriel fronterizo entre las provincias de Valencia y Albacete.

\section{Orden NEURÓPTERA}

\section{$\underline{\text { Familia Ascalaphidae }}$}

Bubopsis agrionoides (Rambur, 1838)

Aistleitner y Lencina Gutiérrez (2020) publican una recopilación de citas de neurópteros entre las que figuran algunas de esta especie, no observada anteriormente en la provincia.

Año 1978: una hembra en la laguna de Ojos de Villaverde (Robledo) el 6 de agosto (J. L. Lencina).

Año 1984: en Lugar Nuevo (Riópar) el 26 de julio y el 13 de agosto se observan tres hembras en ambas ocasiones (E. Aistleitner).

Año 1987: río Mundo (Riópar) un macho y una hembra el 15 de julio (J. L. Lencina). Tus (Yeste), un macho y una hembra el 15 de julio (J. L. Lencina).

Año 1988: Camino a La Vegallera (Riópar) un macho el 1 de agosto (E. Aistleitner). 


\section{Orden COLEOPTERA}

$\underline{\text { Familia Cerambycidae }}$

Xylotrechus stebbingi Gahan, 1906

Especie xilófaga asiática recientemente establecida en la región mediterránea.

Año 2019: un macho y una hembra en actitud reproductiva, sobre el suelo en una calle de La Felipa (Chinchilla de Montearagón), el 4 de septiembre. (Guillermo García-Saúco, publicada en García-Saúco Sánchez, 2019)

\section{$\underline{\text { Familia Chrysomelidae }}$}

\section{Monoxia obesula Blake, 1939}

Especie originaria de América del Norte que ha sido registrada recientemente en Cerdeña, Malta, Baleares y Comunidad Valenciana. Lencina y Miñano (2018) aportan nuevas citas para la provincia de Alicante y primeros registros tanto para la Comunidad de Murcia como para CastillaLa Mancha.

Año 2017: 5 ejemplares ( 3 machos y 2 hembras) en Nava Campana (Hellín), el 21 de agosto sobre Atriplex halimus L. (J. L. Lencina en Lencina y Miñano, 2018).

\section{Orden DIPTERA}

\section{$\underline{\text { Familia Bolitophilidae }}$}

Bolitophila cinerea Meigen, 1818

Año 2003: una hembra el 11 de mayo en la cueva del Farallón (Riópar). Publicada por Carles-Toldrá (2006).

\section{$\underline{\text { Familia Culicidae }}$}

Bueno Marí (2020) publica los resultados de un trabajo de prospección sobre larvas de mosquitos culícidos, realizado entre mayo y agosto de 
2018. El trabajo se realizó en 42 puntos de muestreo repartidos por toda la provincia, formados tanto por masas de agua naturales como por microambientes hídricos en entornos urbanos (fuentes, recipientes domésticos, etc.). Se detectan 15 especies diferentes, de las cuales 11 son consideradas primeras citas para la provincia de Albacete, son las siguientes:

Anopheles maculipennis Meigen, 1818

Anopheles claviger (Meigen, 1804)

Anopheles petragnani Del Vecchio, 1939

Culex theileri Theobald, 1903

Culex impudicus Ficalbi, 1890

Culiseta subochrea (Edwards, 1921)

Culex territans Walker, 1856

Culex hortensis Ficalbi, 1889

Culiseta annulata (Schrank, 1776)

Culex modestus Ficalbi 1889

Culex mimeticus Noe, 1899

$\underline{\text { Familia Helomycidae }}$

Helomyza modesta (Meigen, 1838)

Año 2008: un macho y siete hembras el 3 de mayo en la cueva de la Pedorrilla (Riópar), publicado por Carles-Tolrá y Pérez (2011) como nueva especie para la provincia.

$\underline{\text { Familia Syrphidae }}$

Lorenzo et al. (2019) hacen un muestreo de esta interesante familia en el Jardín Botánico de Castilla-La Mancha entre el 18 de abril y el 28 de mayo de 2018. Además de la importante información obtenida sobre su ecología, de las 18 especies identificadas 12 son nuevas para la fauna albacetense. Dichas especies son:

Syritta flaviventris Macquart, 1842

Scaeva pyrastri (Macquart, 1842) 
Meliscaeva auricollis (Meigen, 1822)

Eristalinus aeneus (Scopoli, 1763)

Chrysotoxum intermedium Meigen, 1822

Platynochaetus setosus (Fabricius, 1794)

Epistrophe eligans (variedad trifasciata) (Harris, 1780)

Eupeodes corollae (Fabricius, 1794)

Paragus tibialis (Fallén, 1817)

Sphaerophoria rueppellii (Wiedemann, 1830)

Eristalinus taeniops (Wiedemann, 1818)

Eristalis similis (Fallén,1817)

\section{Orden TRICHOPTERA}

Zamora-Muñoz y Pérez-Fernández (2012) prospectan tres cavidades del calar del Mundo en busca de tricópteros troglófilos. En una serie de visitas entre los años 2003 y 2011 identifican 57 ejemplares de 6 especies diferentes, 5 de las cuales no habían sido citadas en Albacete. Se especifican a continuación las citas de dichas especies.

\section{Familia Limnephilidae}

Stenophylax crossotus McLachlan, 1884, Año 2003: un macho el 11 de mayo en la cueva del Farallón (Riópar). Año 2011: un macho el 5 de junio y otro el 25 de junio, ambos en la cueva del Farallón

Stenophylax espanioli Schmid, 1957

Año 2005: una hembra el 28 de agosto en la cueva de Los Chorros (Riópar).

Stenophylax fissus (McLachlan, 1875)

Año 2009: una hembra el 30 de agosto en la cueva de La Pedorrilla (Riópar).

Año 2010: una hembra el 22 de agosto en la cueva del Farallón (Riópar). Año 2011: dos machos y dos hembras el 5 de junio en la cueva del Farallón. Una hembra el 25 de junio en la misma cavidad. 
Stenophylax nycterobius (McLachlan, 1875)

Año 2009: 8 machos y 7 hembras el 30 de agosto en la cueva de La Pedorrilla (Riópar).

Stenophylax vibex (Curtis, 1834)

Año 2009: una hembra el 30 de agosto en la cueva de La Pedorrilla (Riópar).

Año 2010: una hembra el 22 de agosto en la cueva del Farallón (Riópar).

\section{Orden LEPIDOPTERA}

Familia Geometridae, Subfamilia Larentiinae

Chloroclysta miata clara (Thierry-Mieg, 1915)

Nueva especie para la provincia.

Año 2018: un macho el 21 de abril y un macho el 7 de junio, ambos en el arroyo de La Celada (Molinicos). Arcas et al. (2019).

Operophtera brumata (Linnaeus, 1758)

Nueva especie para la provincia.

Año 2018: dos machos el 1 de diciembre en el arroyo de La Celada (Molinicos). Arcas et al. (2019).

Familia Geometridae, Subfamilia Alsophilinae

Alsophila aceraria (Denis \& Schiffermüller, 1775)

Nueva especie para la provincia.

Año 2018: un macho el 1 de diciembre en el arroyo de La Celada (Molinicos). Arcas et al. (2019).

Familia Noctuidae, Subfamilia Calpinae

Scoliopteryx libatrix (Linnaeus, 1758)

Año 2010: un ejemplar en invierno en la cueva del Farallón (Riópar). Publicado por Pérez Fernández et al. (2012) como especie troglófila. 
$\underline{\text { Familia Noctuidae, Subfamilia Catocalinae }}$

Autophila dilucida (Hübner, 1808)

Recogemos dos citas publicadas por Pérez Fernández et al. (2012) como especie troglófila.

Año 1995: un ejemplar el 5 de febrero en el interior de la cueva del Farallón (Riópar).

Año 2010: un ejemplar el 8 de agosto en el interior de la cueva de Los Chorros (Riópar).

Apopestes spectrum (Esper, 1787)

Recogemos dos citas publicadas por Pérez Fernández et al. (2012) como especie troglófila.

Año 1995: un ejemplar en el interior de la cueva del Farallón (Riópar) el 5 de febrero.

Año 2010: un ejemplar en la cueva del Farallón (Riópar), el 22 de agosto.

Familia Noctuidae, Subfamilia Hadeninae

Mormo maura (Linnaeus, 1758)

Año 2010: un ejemplar en el interior de la cueva de Los Chorros (Riópar) el 8 de agosto. Publicado por Pérez Fernández et al. (2012) como especie troglófila.

$\underline{\text { Familia Noctuidae, Subfamilia Noctuinae }}$

Lycophotia erythrina (Herrich-Schäffer, 1852)

Nueva especie para la provincia.

Año 2018: un macho el 29 de septiembre en el arroyo de La Celada (Molinicos). Arcas et al. (2019).

Xestia agathina (Duponchel, 1928)

Nueva especie para la provincia.

Año 2018: un macho el 29 de septiembre y otro el 12 de octubre, ambos en el arroyo de La Celada (Molinicos). Arcas et al. (2019). 


\section{Orden HYMENOPTERA}

García y Tinaut (2017) publican los resultados de un muestreo de hormigas realizado entre mayo y agosto de 2016 en la Reserva de Fauna Hazadillas y Era Vieja, adyacente al Parque Natural de las Lagunas de Ruidera. Este trabajo supone la ampliación de la fauna mirmecológica (familia Formicidae) conocida en la provincia de Albacete de 14 a 36 especies. Se enumeran a continuación las 22 nuevas especies para la provincia obtenidas en dicho trabajo:

$\underline{\text { Familia Formicidae, subfamilia Dolichoderinae }}$

Tapinoma nigerrimum complex. Se han obtenido ejemplares de tres especies que han estado confundidas con T. nigerrimum (Nylander, 1856): T. magnum Mayr, 1861; T. ibericum Santschi, 1925 y T. darioi Seifert, D'Eustacchio, Kaufmann, Centorame, Lorite \& Modica, 2017. Los autores prefieren dejar la adscripción taxonómica al complejo de especies $T$. nigerrimum mientras se hace un análisis más detallado de las muestras obtenidas.

$\underline{\text { Familia Formicidae, subfamilia Formicinae }}$

Camponotus cruentatus (Latreille, 1802)

Camponotus lateralis (Olivier, 1792)

Camponotus piceus (Leach, 1825)

Camponotus pilicornis (Roger, 1859)

Cataglyphis iberica (Emery, 1906)

Formica decipiens Bondroit, 1918

Iberoformica subrufa Roger, 1859

Plagiolepis pygmaea (Latreille, 1798)

Plagiolepis schmitzii Forel, 1895

$\underline{\text { Familia Formicidae, subfamilia Myrmicinae }}$

Aphaenogaster dulciniae Emery, 1924

Crematogaster sordidula (Nylander, 1849) 
Solenopsis latro Forel, 1894

Solenopsis fugax (Latreille, 1798)

Messor barbarus (Linnaeus, 1767)

Messor capitatus (Latreille, 1798)

Pheidole pallidula (Nylander, 1849)

Temnothorax formosus Santschi, 1909

Temnothorax racovitzai Brondoit, 1918

Temnothorax recedens (Nylander, 1856)

Tetramorium cf caespitum (Linnaeus, 1758)

Tetramorium semilaeve André, 1883

\section{Phylum Chordata \\ Clase AVES}

\section{Orden ANSERIFORMES}

$\underline{\text { Familia Anatidae }}$

Ánsar campestre

Anser fabalis rossicus (Latham, 1787)

Observaciones de un visitante ocasional en España y Castilla-La Mancha. Año 2019: 1 ave en el río Júcar (Villalgordo del Júcar), el 26 de marzo (Vicente Moreno).

\section{Porrón pardo}

Aythya nyroca (Güldenstädt, 1770)

Observaciones de esta especie "En Peligro de Extinción” en España y Castilla-La Mancha.

Año 2109: 1 macho en la laguna de Los Patos (Hellín), el 15 de marzo (José Antonio Cañizares y Manuel Salas).

\section{Porrón moñudo}

Aythya fuligula Linnaeus, 1758

Especie con escasa observaciones durante los últimos años.

Año 2019: 1 ave de segundo año en la laguna de Salobrejo (Higueruela), el 12 de enero (José Antonio Cañizares y Lucas de las Heras). 


\section{Orden PHOENICOPTERIFORMES}

$\underline{\text { Familia Phoenicopteridae }}$

\section{Flamenco común}

Phoenicopterus roseus Pallas, 1811

Reproducción de la especie en la laguna de Pétrola (Pétrola-Chinchilla de Montearagón) y otras citas fuera del complejo lagunar de Pétrola-Corral Rubio-La Higuera.

Año 2019: Se estiman 400 parejas reproductoras y 18 pollos nacidos, de los que volaron 13 (Juan Picazo); 108 adultos en la nava de los Melchores (El Bonillo), el 7 de mayo (José Antonio Cañizares); 96 en la nava de los Melchores II (El Bonillo), el 18 de mayo (Julia Giménez y Siro González); 35 en la nava de Peribáñez (El Ballestero), el 18 de mayo (Julia Giménez y Siro González).

\section{Flamenco enano}

Phoeniconaias minor (Geoffroy Saint-Hilaire, 1798)

Especie subsahariana. Las citas en diferentes países europeos suelen ser escapes de ejemplares cautivos en colecciones zoológicas. Sin embargo los avistamientos en España, habitualmente dentro de bandos de flamenco común, probablemente se traten de ejemplares divagantes desde sus poblaciones africanas.

Año 2019: 2 ejemplares adultos el 22 de mayo en la laguna de Pétrola (Pétrola-Chinchilla de Montearagón) (Antonio Fajardo y Julián Picazo, cita publicada en Molina et al. 2020).

\section{Orden CICONIIFORMES}

$\underline{\text { Familia Ciconiidae }}$

\section{Cigüeña negra}

Ciconia nigra (Linnaeus, 1758)

Año 2019: 1 ave en el río Júcar en Bolinches (Valdeganga), el día 7 de mayo (Juan Fresneda); 1 en Villarrobledo, el 20 de septiembre (Myriam Mondéjar). 


\section{Orden PELECANIFORMES}

$\underline{\text { Familia Threskiornithidae }}$

\section{Morito común}

Plegadis falcinellus Linnaeus, 1776

Varias citas de esta especie escasa en Albacete.

30 en la laguna de Pétrola (Pétrola y Chinchilla de Montearagón), vistos por Pedro López y Carmen María Martínez el 23 de febrero (eBird https://ebird.org/home); 6 en la laguna del Canal (Albacete), el 30 de marzo (David Cañizares); 1 en La Gila (Alcalá del Júcar), el 3 de abril (Pablo Jutglá); 2 en la laguna del Canal (Albacete), el 7 de mayo (José Antonio Cañizares); 8 en la laguna de los Melchores (El Bonillo), el 7 de mayo (José Antonio Cañizares); 2 en la laguna del Canal (Albacete), el 12 de mayo (Conchi Ríos y Jesús Sánchez); 1 en la Hoya del Pozo (Corral Rubio), visto por Gorka Gorospe el 12 de mayo (eBird https://ebird.org/ home); 7 en la laguna de Casa Palomera (Chinchilla de Montearagón), el 13 de mayo (Juan Picazo); 3 en la laguna de Horna (Chinchilla del Monte Aragón), el 2 de junio (Lucas de las Heras); 3 en la laguna de Horna (Chinchilla de Montearagón), vistos por Lucas de las Heras el 2 de junio (eBird https://ebird.org/home); 2 en la laguna de Pétrola (Pétrola y Chinchilla de Montearagón), el 17 de junio (Juan Picazo); 5 en Hoya Osilla (Chinchilla de Montearagón), el 20 de junio (Agustín Segura); 7 en la laguna de Salobrejo (Higueruela), el 6 de julio (José Antonio Cañizares); 2 en la laguna de Horna (Chinchilla de Montearagón), el 9 de julio (Marcelo Quesada); 1 en la laguna de Horna (Chinchilla de Montearagón), el 14 de julio (Juan Picazo); 4 en la depuradora de Pozohondo, el 12 de agosto (José Antonio Cañizares, Marcos Cañizares y Lucas Cañizares).

\section{Espátula común}

Platalea leucorodia Linnaeus, 1758

Cita de una especie muy escasa en Albacete.

Año 2019: 1 indeterminado en la laguna de Horna (Chinchilla de Montearagón), el 27 de febrero (Agustín Segura, Miguel Velaz, Paco Hidalgo 
y Diego Contreras); 1 en la laguna de Pétrola (Pétrola y Chinchilla de Montearagón), vista por Félix Arribas el 27 de mayo (eBird https://ebird. org/home); 2 aves adultas en el embalse de Camarillas (Hellín), el 24 de mayo (José Antonio Cañizares y Manuel Salas); 1 en la laguna de Horna (Chinchilla de Montearagón), el 9 de julio (Marcelo Quesada); 1 en la misma laguna de Horna (Chinchilla de Montearagón), el 14 de julio (Juan Picazo).

$\underline{\text { Familia Ardeidae }}$

\section{Garcilla cangrejera}

Ardeola ralloides (Scopoli, 1769)

Citas en los humedales de Albacete de esta especie "En Peligro de Extinción" en Castilla-La Mancha.

Año 2019: 1 en la laguna de Los Patos (Hellín), vista por Vicente Hernández el 12 de agosto (eBird https://ebird.org/home).

\section{Garza imperial}

Ardea purpurea Linnaeus, 1766

Citas de una especie escasa en Albacete.

Año 2019: 1 ave en la laguna de Ontalafia (Albacete), el 27 de marzo (Juan Picazo); 1 también en la laguna de Ontalafia (Albacete), el 1 de abril (Juan Picazo); 3 adultos en los Ojos de Villaverde (Robledo), el 31 de mayo (Agustín Segura); 2 aves en idéntico lugar a la cita anterior, el 10 de junio (Agustín Segura).

\section{Garceta grande}

Ardea alba (Linnaeus, 1758)

Observaciones de una especie escasa.

Año 2019: 1 adulto en la laguna de Horna (Chinchilla de Montearagón), el 27 de mayo (Juan Picazo); 1 adulto en la laguna de Horna (Chinchilla de Montearagón), el 30 de mayo (Juan Picazo); 1 adulto también en la laguna de Horna (Chinchilla de Montearagón), el 2 de junio (Lucas de las Heras); 1 en la laguna de Horna (Chinchilla de Montearagón), respectivamente los días 25 y 30 de mayo, y 17 y 25 de junio (Juan Picazo); 2 en la 
laguna de San Benito (Almansa), el 23 de octubre (José Antonio Cañizares); 1 en la laguna de Pétrola (Pétrola y Chinchilla de Montearagón), el 3 de diciembre (José Antonio Cañizares); 1 en laguna de Pétrola (Pétrola y Chinchilla de Montearagón), vista por Oriol Palau, Jana Marco, Alex Alamán y Julio Merayo el 29 de diciembre (eBird https://ebird.org/home).

\section{Orden ACCIPITRIFORMES}

$\underline{\text { Familia Pandionidae }}$

\section{Águila pescadora}

Pandion haliaetus (Linnaeus, 1758)

Año 2019: 1 individuo al anochecer en La Higuera (Corral Rubio), el 22 de febrero (Juan Picazo); 1 en Riópar Viejo (Riópar), vista por Rafael Torralba el 27 de marzo (eBird https://ebird.org/home); 1 en La Roda, vista por Rafael Torralba el 30 de marzo (eBird https://ebird.org/home); 1 en el embalse de La Fuensanta (Yeste), el 20 de abril (Marcelo Quesada); 1 en Casas de Juan Núñez, el 21 de abril (Vicente Moreno); 1 en El Bachiller (Corral Rubio), el 18 de septiembre (Manuel Salas); 1 en la laguna de Pétrola (Pétrola y Chinchilla de Montearagón), vista por Rafael Torralba el 18 de septiembre (eBird https://ebird.org/home); 1 en Las Tiesas (Albacete), vista por Rafael Torralba el 19 de septiembre (eBird https:// ebird.org/home).

\section{$\underline{\text { Familia Accipitridae }}$}

\section{Elanio común}

Elanus caeruleus (Desfontaines, 1789)

Citas estivales de esta especie invernante.

Año 2019: 1 en Reolid (Salobre), el 26 de abril (Lucas de las Heras); 1 en el Cortijo de Gorgojil (Alcaraz), el 10 de junio (Agustín Segura).

\section{Quebrantahuesos}

Gypaetus barbatus Linnaeus, 1758

Citas de esta rapaz "En Peligro de Extinción”. 
Año 2019: 2 (adulto e inmaduro) en Vianos, vistos por Álvaro García el 9 de febrero (eBird https://ebird.org/home); 1 ave en el cerro del Agua (Nerpio), el 17 de febrero (Alfonso Samper); 1 en la Reserva Natural Sierra de Las Cabras (Nerpio), el 12 de mayo (Sergio Ovidio Pinedo y Alfonso Samper); 1 en el nacimiento del río Mundo (Riópar), visto por Rafael Torralba el 25 de mayo (eBird https://ebird.org/home); 1 en el barranco de Artuñio (Nerpio), el 15 de junio (Lucas de las Heras y José Antonio Cañizares); 1 en el Padroncillo (Riópar), visto por Rafael Torralba el 28 de junio (eBird https://ebird.org/home); 1 juvenil hallado muerto en Munera, por Agentes Medioambientales de la JJ.CC. de Castilla-La Mancha el 5 de julio; 1 en La Gineta, recogido con signos de deshidratación el 17 de agosto por Agentes Medioambientales de la JJ.CC. de Castilla-La Mancha y trasladado al Centro de Recuperación de Fauna Salvaje de Albacete; 1 en los Poyos (Nerpio), el 7 de diciembre (Alfonso Samper Lozano y Alfonso Samper Cervera); 1 en Mingarnao (Nerpio), el 18 de diciembre (Marcelo Quesada).

\section{Alimoche Común}

Neophron percnopterus (Linnaeus, 1758)

Citas de este buitre escaso en Albacete.

Año 2019: 1 en el nacimiento del río Mundo (Riópar), visto por Rafael Torralba el 17 de agosto (eBird https://ebird.org/home).

\section{Buitre negro}

Aegypius monachus (Linnaeus, 1766)

Citas de este buitre con muy pocas observaciones en Albacete.

Año 2019: 1 en Alcaraz, visto por Rafael Torralba el 1 de enero (eBird https://ebird.org/home); 4 en la sierra del Relumbrar (Villapalacios), vistos por Rafael Torralba el 1 de enero (eBird https://ebird.org/home); 1 en la sierra del Relumbrar (Villapalacios), visto por Rafael Torralba el 4 de enero (eBird https://ebird.org/home); 4 en la sierra del Relumbrar (Villapalacios), vistos por Rafael Torralba el 7 de enero (eBird https://ebird. org/home); 1 en el nacimiento del río Mundo (Riópar), visto por Rafael Torralba el 5 de mayo (eBird https://ebird.org/home); 1 ave en la Solana de las Covachas (Nerpio), el 1 de junio (Sergio Ovidio Pinedo y Alfonso Samper); 1 en Yeste, el 26 de noviembre (Jesús Muñoz). 
Águila imperial ibérica

Aquila adalberti (Brehm, 1981)

Rapaz catalogada "En Peligro de Extinción".

Año 2019: 7 (4 adultos, 1 damero y 2 pajizos) en la sierra del Relumbrar (Villapalacios), vistos por Rafael Torralba el 1 de enero (eBird https:// ebird.org/home); 2 en la Casa de las Tasoneras (La Roda), el 4 de enero (José Antonio Cañizares, David Cañizares, Agustín Segura, Pablo Segura y Lucas de las Heras); 1 en Santa Marta (La Roda), el 4 de enero (José Antonio Cañizares y David Cañizares); 4 en la sierra del Relumbrar (Villapalacios), vistas por Rafael Torralba el 4 de enero (eBird https://ebird.org/home); 1en el calar del Mundo (Riópar), vista por Álvaro García el 6 de enero (eBird https://ebird.org/home); 5 en la sierra del Relumbrar (Villapalacios), vistas por Rafael Torralba el 7 de enero (eBird https://ebird.org/home); 1 en la sierra del Relumbrar (Villapalacios), vista por Lucas de las Heras el 11 de enero (eBird https://ebird.org/ home); 2 en La Dehesa de Los Llanos (Albacete), vistas por Rafael Torralba el 15 de enero (eBird https://ebird.org/home); 6 (4 adultos, 1 damero y 1 pajizo) en la sierra del Relumbrar (Villapalacios), vistos por Rafael Torralba-Actio Birding el 26 de enero (eBird https://ebird.org/home); 1 en la sierra de Ontalafia (Albacete), el 30 de enero (Juan Picazo y participantes del Grupo senderismo y aves, de la Universidad Popular); 2 en las Salinas de Pinilla (Viveros), vistas por Rafael Torralba-Actio Birding el 1 de febrero (eBird https://ebird.org/home); 1 en el Cilanco (Villatoya), el 3 de febrero (Lucas de las Heras); 1 en El Regajo (Pozuelo), vista por Rafael Torralba-Actio Birding el 7 de febrero (eBird https://ebird. org/home); 2 pajizos en la sierra del Relumbrar (Villapalacios), vistas por José Antonio Sánchez el 9 de febrero (eBird https://ebird.org/home); 1 en Horna (Chinchilla de Montearagón), vista por Gabino Cortés el 24 de febrero (eBird https://ebird.org/home); 3 en la Casa de la Encomienda (Balazote), vistas por Rafael Torralba y Virgilio Beltrán-Actio Birding el 3 de marzo (eBird https://ebird.org/home); 4 (3 adultos y 1 pajizo) en la sierra del Relumbrar (Villapalacios), vistos por Rafael Torralba el 9 de marzo (eBird https://ebird.org/home); 1 en Cañada Molina (Peñas de San Pedro), el 16 de marzo (José María García); 1 en Argamasón (Pozuelo), el 22 de marzo (José Antonio Cañizares y Manuel Salas); 1 en Las 
Anorias (Pétrola), visto por Rafael Torralba el 10 de abril (eBird https:// ebird.org/home); 1 en Balazote, el 13 de abril (Agustín Segura); 1 en la laguna de Acequión (Albacete), el 21 de abril (José Antonio Cañizares); 1 en Las Tiesas (Albacete), el 24 de abril (Daniel López); 1 en la sierra de Enmedio (Albacete), el 30 de abril (Juan Picazo); 2 adultos en el Cerrón (Ituero, Masegoso), el 15 de mayo (Juan Picazo); 1 en el nacimiento del río Mundo (Riópar), vista por Rafael Torralba-Actio Birding el 4 de mayo (eBird https://ebird.org/home); 1 en la ETAD Aguas de Albacete (Albacete) el 22 de mayo (Lucas de las Heras); 1 en Casa Villora (Chinchilla del Monte Aragón), el 23 de mayo (Raúl Galindo); 4 en la sierra del Relumbrar (Villapalacios), vistos por Rafael Torralba el 10 de junio (eBird https://ebird.org/home); 2 en la laguna del Arquillo (Robledo), el 17 de julio (Félix Muñoz); 2 en la sierra del Relumbrar (Villapalacios), vistos por Rafael Torralba el 26 de julio (eBird https://ebird.org/home); 1 el Cerro Morote (Pozo Cañada), vista por Antonio Varona el 22 de agosto (eBird https://ebird.org/home); 4 en la Casa de las Tasoneras (La Roda) el 5 de septiembre (José Antonio Cañizares Mata y Ángel Domingo); 1 damero en Moharras (Villarrobledo), el 5 de septiembre (José Antonio Cañizares y Ángel Domingo Collado); 2 en Carro (Munera), el 5 de septiembre (José Antonio Cañizares y Ángel Domingo Collado); 1 en Santa Marta (La Roda), el 6 de septiembre (José Antonio Cañizares y Ángel Domingo Collado); 3 en la sierra del Relumbrar (Villapalacios), vistas por Rafael Torralba el 8 de septiembre (eBird https://ebird.org/home); 1 en Las Tiesas (Albacete), vista por Rafael Torralba el 19 de septiembre (eBird https://ebird.org/home); 2 en Blancares Nuevos (Albacete), vistas por Javier García el 22 de septiembre (eBird https://ebird.org/home); 1 en Cañada Blanquilla (Casas de Lázaro), el 25 de septiembre (Juan Picazo y participantes del Grupo senderismo y aves, de la Universidad Popular de Albacete); 1 en Santa Marta (La Roda), vista por Yanina Maggiotto el 1 de octubre (eBird https://ebird.org/home); 3 en la Sierra del Relumbrar (Villapalacios), el 10 de octubre (Manuel Salas); 1 individuos en La Molata y los Batanes (Alcaraz), vista por Rafael Torralba el 17 de julio (eBird https://ebird.org/home); 1 en la Peña del Águila (Casas de Lázaro), vista por Fernando Alonso el 18 de octubre (eBird https://ebird. org/home); 2 en el camino a Casa Berruga (Munera), vistas por David 
Cantalejo y Jon Iratzagorría el 13 de noviembre (eBird https://ebird.org/ home); 6 (4 adultos) en la sierra del Relumbrar (Villapalacios), vistos por Rafael Torralba el 1 de diciembre (eBird https://ebird.org/home); 1 en el Estrecho del Hocino (Salobre), vista por Rafael Torralba el 1 de diciembre (eBird https://ebird.org/home); 2 en El Cepillo (Alcaraz), el 30 de diciembre (Julia Giménez y Siro González).

\section{Aguilucho lagunero occidental}

Circus aeruginosus (Linnaeus, 1758)

Cita de un número relevante de aves.

Año 2019: 84 individuos en la laguna de Salobrejo (Higueruela), el 12 de enero al amanecer (José Antonio Cañizares y Lucas de las Heras).

\section{Aguilucho papialbo}

Circus macrourus Gmelin, 1770

Nueva observación de la especie en Albacete. $\left(^{*}\right)$ Cita sometidas a homologación.

Año 2019: 1 macho en la laguna Ojos de Villaverde (Robledo), visto por Rafael Torralba el 26 de enero (eBird https://ebird.org/home).

\section{Milano real}

Milvus milvus (Linnaeus, 1758)

Citas de esta rapaz "En Peligro de Extinción".

Año 2019: 1 en las salinas de Pinilla (Viveros), visto por Rafael Torralba el 1 de enero (eBird https://ebird.org/home); 1 en la sierra del Relumbrar (Villapalacios), visto por Rafael Torralba y José Vicente Navarro el 1 de enero (eBird https://ebird.org/home); 2 en Casa del Llano (El Bonillo), vistos por José Vicente Navarro el 4 de enero (eBird https://ebird. org/home); 43 en la Casa de las Tasoneras (La Roda), el 4 de enero (José Antonio Cañizares, David Cañizares, Agustín Segura, Pablo Segura y Lucas de las Heras); 134 en la Casa de la Espartosilla (El Bonillo), el 4 de enero (Julia Giménez, Siro González, Miguel Vélaz, Francisco Tornero y Noé Cuesta); 1 en Salobrejo (Higueruela), visto por Rafael Torralba el 5 de enero (eBird https://ebird.org/home); 4 en Montalvos, vistos por Rafael Torralba el 11 de enero (eBird https://ebird.org/home); 4 en Blan- 
cares Nuevos (Albacete), vistos por Rafael Torralba-Actio Birding el 13 de enero (eBird https://ebird.org/home); 1 en Montalvos, visto por Rafael Torralba el 13 de enero (eBird https://ebird.org/home); 1 en Bolinches (Valdeganga), el 10 de febrero (Ángel Camacho y Juan Camacho); 2 en Montalvos, vistos por Rafael Torralba-Actio Birding el 10 de febrero (eBird https://ebird.org/home); 2 en Minaya, el 12 de febrero (Agustín Segura); 1 en Fuensanta, el 14 de febrero (José Manuel Reolid); 17 en Moharras (Villarrobledo), el 16 de febrero (Lucas de las Heras); 2 en La Marmota (Tarazona de La Mancha), el 17 de febrero (Ángel Camacho y Juan Camacho); 1 en la laguna de Tinajeros (Albacete), el 21 de febrero (Agustín Segura); 6 en La Gineta (La Gineta), el 24 de febrero (Noé Cuesta); 2 en Casa del El Monte (Valdeganga), el 25 de febrero (Agustín Segura); 1 en la laguna de Tinajeros (Albacete), el 4 de marzo (José Antonio Cañizares y Marcos Cañizares); 6 en la Huerta de Marta (Tarazona de La Mancha), vistos por Rafael Torralba el 6 de marzo (eBird https://ebird. org/home); 1 en Pasaconsol (Villarrobledo), visto por José Gómez el 14 de marzo (eBird https://ebird.org/home); 1 en Bonete (Bonete), visto por Yanina Maggiotto el 26 de marzo (eBird https://ebird.org/home); 1 en Montalvos, visto por Rafael Torralba el 3 de abril (eBird https://ebird. org/home); 1 en Bonete, visto por Yanina Maggiotto el 4 de abril (eBird https://ebird.org/home); 1 en Pozo Cañada, visto por Guillermo Gómez el 14 de abril (eBird https://ebird.org/home); 1 en Las Tiesas (Albacete), el 24 de abril (Daniel López); 1 en Letur, el 25 de mayo (David Cañizares); 1 en el nacimiento del río Mundo (Riópar), visto por Rafael Torralba el 28 de julio (eBird https://ebird.org/home); 1 en Cuasiermas (Albacete), visto por Juan José Lucas el 2 de octubre (eBird https://ebird.org/ home); 2 en la laguna de Pétrola (Pétrola), vistos por Josep Puentes el 9 de octubre (eBird https://ebird.org/home); 1 en Cuasiermas (Albacete), visto por Juan José Lucas el 11 de noviembre (eBird https://ebird. org/home); 3 en el camino a Casa Berruga (Munera), vistos por David Cantalejo y Jon Iratzagorría el 13 de noviembre (eBird https://ebird.org/ home); 2 en el Bachiller (Bonete), vistos por Virgilio Beltrán el 16 de noviembre (eBird https://ebird.org/home); 1 en La Torrecica (Corral Rubio), visto por Martin O'Hanlon el 19 de noviembre (eBird https://ebird. org/home); 1 en Cuasiermas (Albacete), visto por Juan José Lucas el 27 de 
diciembre (eBird https://ebird.org/home); 106 en Navas de Jorquera, el 6 de diciembre (Julia Giménez y Siro González); 209 en Sotuélamos (El Bonillo), el 30 de diciembre (Julia Giménez y Siro González).

\section{Orden GRUIFORMES}

$\underline{\text { Familia Rallidae }}$

\section{Calamón común}

Phorphyrio phorphyrio (Linnaeus, 1758)

Citas de reproducción comprobadas y localidades con pocas citas.

Año 2019: 1 en la depuradora de Bonete, visto por Cristina Martínez y Quela Atienza el 13 de abril (eBird https://ebird.org/home); pareja con 2 pollos pequeños en la laguna de Ontalafia (Albacete), el 13 de abril (Juan Picazo); una pareja con 4 pollos medianos en la laguna de Salobrejo (Higueruela), el 6 de julio (José Antonio Cañizares); 1 en la depuradora de Bonete, visto por Virgilio Beltrán el 5 de agosto (eBird https://ebird.org/ home); 1 adulto con 1 juvenil en la laguna de Ontalafia (Albacete), el 23 de agosto (Juan Picazo).

\section{Focha moruna}

Fulica cristata Gmelin, 1789

Cita de esta especie "En Peligro de Extinción" en y Castilla-La Mancha. Año 2019: 1 en la Hoya del Pozo (Corral Rubio), vista por Xurxo Piñeiro el 12 de febrero (eBird https://ebird.org/home).

\section{Orden CHARADRIIFORMES}

\section{Familia Charadriidae}

\section{Chorlito dorado europeo}

Pluvialis apricaria (Linnaeus, 1758)

Invernante escaso en la provincia. Más abundante en pasos migratorios. A menudo formando bandos mistos con avefría.

Año 2019: 18 ejemplares integrados en un grupo de varias decenas de 
avefrías y estorninos, el 18 de diciembre al norte de Tinajeros (Albacete) (Carmen Oliver y Julián Picazo).

\section{Chorlito gris}

Pluvialis squatarola (Linnaeus, 1758)

Especie muy escasa como migrante en el interior de la península Ibérica. Año 2019: 1 ave en la laguna de Pétrola (Pétrola y Chinchilla de Montearagón), el 3 de diciembre (José Antonio Cañizares).

\section{Chorlito carambolo}

Charadrius morinellus (Linnaeus, 1758)

Migrador escaso en la provincia de Albacete.

Año 2019: 16 en el Llano de Riachuelos (Albacete), vistos por Luis Carretero el 28 de marzo (eBird https://ebird.org/home); 34 individuos en Las Tiesas (Albacete), el 2 de abril (Manuel Salas y Jacinto Colmenero); 31 en Blancares Nuevos (Albacete), vistos por Rafael Torralba el 3 de abril (eBird https://ebird.org/home); 187 aves en Las Tiesas (Albacete), el 4 de septiembre (José Antonio Cañizares y Manuel Salas); 2 en Santa Marta (La Roda), el 6 de septiembre (José Antonio Cañizares y Ángel Domingo Collado); 40 en Aldea Nueva (Chinchilla), el 9 de septiembre (José Antonio Cañizares y Ángel Domingo Collado); 9 aves en El Rochal (Chinchilla), también el 9 de septiembre (José Antonio Cañizares y Ángel Domingo Collado); 100 en Las Tiesas (Albacete), vistos Javier García el 22 de septiembre (eBird https://ebird.org/home); 200 en Hondoneros (Barrax), vistos por José Velasco el 22 de septiembre (eBird https://ebird. org/home); 216 también en Las Tiesas, vistos por Rafael Torralba en 22 de septiembre (eBird https://ebird.org/home); 120 en el Moral (Albacete), vistos por Yanina Maggiotto el 1 de octubre (eBird https://ebird.org/ home); 117 en el Moral (Albacete), vistos por Josep Puentes el 9 de octubre (eBird https://ebird.org/home); 130 en Las Tiesas (Albacete), vistos por Jordi Marqués y Juan Carlos Bellido el 9 de octubre (eBird https:// ebird.org/home); 37 en la estación de Bonete, vistos por James Spencer el 28 de octubre (eBird https://ebird.org/home); 13 en Casa Higinio (Corral Rubio), vistos por Martin O’Hanlon el 19 de noviembre (eBird https://ebird.org/home). 
$\underline{\text { Familia Scolopacidae }}$

\section{Aguja colipinta}

Limosa lapponica (Linnaeus, 1758)

Cita de un limícola con presencia ocasional en Albacete, con citas muy escasas y de pocos ejemplares.

Año 2019: 1 ave en la laguna de Pétrola (Pétrola y Chinchilla de Montearagón), el 27 de abril (Manuel Salas).

\section{Correlimos gordo}

Calidris canutus (Linnaeus, 1758)

Limícola muy escasa en el interior peninsular.

Año 2019: 6 individuos en el cerro de las Viñas (Pétrola), el 18 de septiembre (Manuel Salas); 4 en la laguna de Pétrola (Pétrola y Chinchilla de Montearagón), vistos por Rafael Torralba y José Velasco el 21 de septiembre (eBird https://ebird.org/home); 4 la laguna de Horna (Chinchilla de Montearagón), vistos por Javier García el 21 de septiembre (eBird https:// ebird.org/home).

\section{Correlimos de Temminck}

Calidris temminckii (Leisler, 1812)

Cita de un limícola escaso como migrante en el interior de la península Ibérica.

Año 2019: 2 aves en Las Tiesas (Albacete), el 3 de mayo (José Antonio Cañizares y Manuel Salas); 2 en el mismo lugar, el 6 de mayo (Manuel Salas).

\section{Correlimos tridáctilo}

Calidris alba (Pallas, 1768)

Especie con escasa citas en Albacete.

Año 2019: 3 individuos en laguna de Pétrola (Pétrola y Chinchilla de Montearagón), vistos por Gorka Gorospe el 12 de mayo (eBird https:// ebird.org/home); 1 en la laguna de Pétrola (Pétrola y Chinchilla de Montearagón), visto por Rafael Torralba el 21 de septiembre (eBird https:// ebird.org/home). 


\section{Chocha perdiz}

Scolopax rusticola (Linnaeus, 1758)

Especie con escasa citas en Albacete.

Año 2019: 1 individuo en el río Guadalmena (Villapalacios), visto por Rafael Torralba el 7 de enero (eBird https://ebird.org/home).

\section{Falaropo picofino}

Phalaropus lobatus Linnaeus, 1758

Especie de limícola ocasional en Iberia, con escasa citas en el interior peninsular.

Año 2019: 1 en la laguna de Pétrola (Pétrola y Chinchilla de Montearagón), observado el 1 de diciembre por Toni Zaragocí, Antonio Bañuls, David Bañuls y Gaspar Bañuls (Fernando Camuñas, Anuario ornitológico on line de Albacete); visto de nuevo en el mismo lugar, el día siguiente al indicado (Lucas de las Heras y Manuel Salas).

\section{$\underline{\text { Familia glareolidae }}$}

\section{Canastera común}

Glareola pratincola (Linnaeus, 1766)

Especie con escasas citas en Albacete.

Año 2019: 6 aves en las Tiesas (Albacete), el 24 de abril (Daniel López); 2 en el mismo lugar el 3 de mayo y 1 individuo el día 7 del mismo mes (José Antonio Cañizares). Entre abril y junio se comprueba la reproducción de 3 parejas en Blancares Viejos (Albacete) y 5 parejas en La Choriza (La Herrera) (Ángel Domingo Collado, Carmen Oliver y Julián Picazo).

\section{$\underline{\text { Familia Laridae }}$}

\section{Gaviota cabecinegra}

Larus melacephalus Temminck, 1820

Nuevos datos de reproducción.

Año 2019: se estiman 3 parejas nidificantes en la isla mayor de la laguna de Pétrola (Pétrola y Chinchilla de Montearagón), el día 17 de junio (Juan Picazo). 


\section{Pagaza piconegra}

Gelochelidon nilotica (Gmelin, 1789)

Número sobresaliente de aves nidificantes.

Año 2019: se estiman 517 parejas nidificantes en las islas mayor y menor de la laguna de Pétrola (Pétrola-Chinchilla de Montearagón), el día 3 de junio (Juan Picazo).

\section{Fumarel cariblanco}

Chlidonias hybrida (Pallas, 1811)

Nuevas localidades de cría.

Año 2019: 8 aves en colonia de cría con al menos 4 nidos ocupados en la laguna de Los Melchores (El Bonillo), el 11 de junio (José Antonio Cañizares).

\section{Fumarel común}

\section{Chlidonias niger (Temminck, 1815)}

Año 2019: 2 aves en el pastizal del Cerro de Las Viñas (Corral Rubio), el 21 de abril (José Antonio Cañizares); 1 en la nava de Los Melchores (El Bonillo), el 7 de mayo (José Antonio Cañizares); 20 en la laguna de Pétrola (Pétrola y Chinchilla de Montearagón), el 2 de junio (Lucas de las Heras y Grupo de iniciación a las aves de la Universidad Popular de Yecla); 2 en la laguna Baños de San José (Corral Rubio), en la misma fecha anterior (Lucas de las Heras y Grupo de iniciación a las aves de la Universidad Popular de Yecla).

\section{Orden STRIGIFORMES}

\section{$\underline{\text { Familia Strigidae }}$}

\section{Búho campestre}

Asio flammeus (Pontoppidan, 1763)

Citas de esta rapaz nocturna tan escasa en Albacete.

Año 2019: 1 en el Haza de los Pegujares (El Bonillo), visto por Rafael Torralba el 1 de enero (eBird https://ebird.org/home); 2 aves cerca de la laguna de Tinajeros (Albacete), el 12 de enero (José Antonio Cañizares, Marcos Cañizares, Lucas Cañizares y Lucas de las Heras). 


\section{Orden FALCONIFORMES}

$\underline{\text { Familia Falconidae }}$

\section{Cernícalo patirrojo}

Falco vespertinus Linnaeus, 1766

Especie distribuida por Europa oriental que se presenta ocasionalmente en la península ibérica durante sus migraciones.

Año 2019: una hembra el 24 de abril al norte de Tinajeros (Albacete) (Carmen Oliver y Julián Picazo).

\section{Halcón de Eleonora}

Falco eleonorae Gené, 1839

Especie de falcónido con pocas citas en Albacete.

Año 2019: 1 individuo en La Molata y los Batanes (Alcaraz), visto por Rafael Torralba el 17 de julio (eBird https://ebird.org/home).

\section{Orden PASSERIFORMES}

$\underline{\text { Familia Acrocephalidae }}$

\section{Zarcero beréber}

Iduna opaca (Cabanis, 1850)

Especie estival escasa en Albacete.

Año 2019: 1 individuo en Cubas (Jorquera), el 12 de julio (José Antonio Cañizares).

\section{$\underline{\text { Famila Locustellidae }}$}

\section{Buscarla pintoja}

Locustella naevia Boddaert, 1783

Especie rara en Albacete como estival y con población migrante escasa, sólo algunos años.

Año 2019: 1 ave en la laguna del Canal (Albacete), el 5 de octubre (Domingo Blanco). 


\section{Buscarla unicolor}

Locustella luscinioides Savi, 1824

Especie rara en Albacete como estival y con población migrante escasa, sólo algunos años.

Año 2019: 1 ave en la laguna del Canal (Albacete), el 27 y 29 de junio (José Antonio Cañizares); 2 en la laguna del Canal (Albacete), el 5 de julio (José Antonio Cañizares y Marcelo Quesada); 1 en la laguna del Canal (Albacete), el 10 de agosto (José Antonio Cañizares); 1 en la laguna de Salobrejo (Higueruela), el 10, 13 y 15 de agosto (José Antonio Cañizares y Marcos Cañizares); 1 en la laguna del Canal (Albacete), el 31 de agosto (Domingo Blanco).

$\underline{\text { Familia Muscicapidae }}$

\section{Roquero rojo}

Monticola Saxatilis (Linnaeus, 1766)

Cita de una especie poco común en Albacete.

Año 2019: 2 aves en el Calar del Mundo (Riópar), vistos por Rafael Torralba el 5 de julio (eBird https://ebird.org/home).

Famila Passeridae

\section{Gorrión moruno}

Passer hispaniolensis Temminck, 1820

Citas con número relevante de aves.

Año 2019: 100 aves en el saladar de Cordovilla (Tobarra), el 15 de marzo (José Antonio Cañizares y Manuel Salas).

\section{Familia PRUNELLIDAE}

\section{Acentor alpino}

Prunella collaris (Scolopi, 1769)

Citas de una especie poco común en Albacete.

Año 2019: 2 aves en el Vado de Tus (Yeste), el 3 de febrero (Jesús Muñoz); 6 en el embalse de La Fuensanta (Yeste), el 22 de febrero (Lucas de las He- 
ras); 1 en el pico de la Sagra (Villaverde), el 24 de febrero (José Antonio Cañizares); 29 aves en el Padroncillo (Riópar), vistos por Rafael Torralba el 30 de noviembre (eBird https://ebird.org/home); 1 en Llano Majano (Yeste), el 6 de diciembre (Jesús Muñoz); 1 en el Castillo de Chinchilla (Chinchilla de Montearagón), el 8 de diciembre (Ángel Camacho y Juan Camacho).

$\underline{\text { Familia Motacillidae }}$

\section{Bisbita arbóreo}

Anthus trivialis, Linnaeus, 1758

Especie con escasas citas en Albacete.

Año 2019: 1 ave en el Jardín Botánico de Castilla-La Mancha (Albacete), visto por Lucas de las Heras el 17 de septiembre (eBird https://ebird.org/ home).

\section{$\underline{\text { Famila Fringillidae }}$}

\section{Pinzón real}

Fringilla montifringilla Linnaeus, 1758

Especie con escasas citas en Albacete.

Año 2019: 2 en Alcaraz, vistos por Rafael Torralba el 1 de enero (eBird https://ebird.org/home); 1 ave en la Casa de las Chozas (Tobarra), el 15 de febrero (José Antonio Cañizares); 3 en el Toyo (Valdeganga), el 23 de octubre (José Antonio Cañizares y Manuel Salas); 4 en Montalvos, el 8 de noviembre (Manuel Salas); 7 en Casa Malpelo (Albacete), el 26 de noviembre (Agustín Segura). 


\section{BIBLIOGRAFÍA}

Aistleitner, E. y Lencina Gutiérrez, F. (2020). On the knowledge of the lacewings fauna in the Spanish province of Albacete (I) (Neuroptera, Nemopteridae, Ascalaphidae). Mitt. internat. entomol. Ver., 43 (3/4): 97-16.

Álvarez Fidalgo, M., Miralles-Núñez, A. y Domenech Fernández, M. (2018). Primeros registros de Sympetrum sinaiticum Dumont, 1977 (Odonata, Libellulidae) en la provincia de Albacete (Castilla-La Mancha, SE España) y actualización de su distribución en España. Boletín de la Asociación Española de Entomología, 42 (3-4): 333-349. Arcas, F., Guerrero, J.J. y Sánchez, J. F. (2019). Cinco nuevas especies para la fauna de Macrolepidoptera (Insecta: Lepidoptera) de la provincia de Albacete (España). Boletín de la Sociedad Aragonesa de Entomología, 29: 180-185.

Bueno Marí, R. (2020). Aportes sobre la fauna de mosquitos culícidos (Diptera, Culicidae) de la provincia de Albacete. Boletín de la Asociación Española de Entomología, 44 (3-4): 275-286.

Camuñas Mohinelo, F. y Álvarez Fidalgo, M. (2018). Primer registro de Anax ephippiger (Burmeister, 1839) en la provincia de Albacete (Castilla-La Mancha, sureste de España) (Odonata: Aeshnidae). Biodiversidad Virtual News Publicaciones Científicas, 7 (100): 146150.

Carles-Toldrá, M. (2006). Citas nuevas de dípteros para la Península Ibérica (Diptera). Boletín de la Sociedad Entomológica Aragonesa, 38: 317-319.

Carles-Toldrá, M. y Pérez, T (2011). Algunos dípteros capturados por el GEV en cuevas del sur peninsular (España). Monografías Bioespeleológicas, 6: 3.

Díaz-Martínez, C., Cardo-Maeso, N., Toledo-Sevilla, B., Simarro-Tórtola, J. y Brotóns-Padilla, M. (2018). Catálogo provisional de los odonatos (Insecta: Odonata) de Castilla-La Mancha (centro de España). Boletín de la Sociedad Entomológica Aragonesa, 63: 325-335.

Evangelio Pinach, J. M. y Torres López, J. (2020). Primeras citas de Platycnemis acutipennis Selys, 1841 (Odonata, Platycnemididae) de la 
provincia de Albacete (sureste de la península ibérica). Boletín de la Asociación Española de Entomología, 44 (1-2): 245-249.

García,M.J.yTinaut,A.(2017).Contribuciónalconocimientodelashormigas (Hymenoptera, Formicidae) de las Lagunas de Ruidera (España). Boletín de la Asociación Española de Entomología, 41 (3-4): 311-327. García-Saúco Sánchez, G. (2019). Primera cita de Xylotrechus stebbingi Gahan, 1906 (Coleoptera, Cerambycidae) en la provincia de Albacete (España). Boletín de la Asociación Española de Entomología, 43 (3-4): 305-307.

Gracia, E., Honrubia, M. y Llimona, X. (1981). Aportación al conocimiento de los hongos del SE de España II. Mixomicetes de la provincia de Albacete. Anales de la Universidad de Murcia Ciencias, 37: 63-79.

Grand, D. 2013. Les libellules du rio Cabriel, provinces d'Albacete, Cuenca et Valencia (Espagne) (Odonata): distribution et observations biologiques. Martinia, 29 (1): 1-8.

Lencina, J. L. y Miñano, J. (2018). Colaphellus sophiae (Schaller 1783) primer registro para España continental y nuevos datos de Monoxia obesula Blake 1939 (Coleoptera: Chrysomelidae). Revista gaditana de Entomología, IX (1): 13-16.

López-Sánchez, E., Honrubia, M. Gracia, E. y Gea, F. J. (1986). Notas sobre los mixomicetos del Sudeste español. Bol. Soc. Micol. Madrid, 11(1): 11-19.

Lorenzo, D., Santiago, A., y Ricarte, A. (2019). El Jardín Botánico de Castilla-La Mancha (Albacete, España), refugio de un grupo bioindicador: los sírfidos (Diptera, Syrphidae). Cuadernos de Biodiversidad, 56: 15-25.

Molina, B., Prieta, J., Lorenzo, J. A. y López-Jurado, C. (2020). Noticiario ornitológico. Ardeola, 67 (1): 185-227.

Pérez Fernández, T., Yela, J. L. y Lencina Gutiérrez, J. L. (2012). Lepidópteros de las cuevas de Los Chorros y El Farallón (Calar del Río Mundo, Riópar, Albacete, España). Arquivos Entomolóxicos, 7: 197-200.

Roldán, A. y Honrubia, M. (1992). Catalogo actualizado de los hongos superiores de la provincia de Albacete. Instituto de Estudios Albacetenses. Albacete. 132 pp. 
Salamanca Ocaña, J. C., Pruiner, F. y Vieira, S. (2013). Faunística de odonatos en la red fluvial de la cuenca del Guadalimar. Boletín Rola, 2: 26-47.

Zamora-Muñoz, C. y Pérez-Fernández, T. (2012). Los tricópteros (Trichoptera, Limnephilidae) de las cavidades del Calar del Mundo (Riópar, Albacete). Boletín de la Asociación Española de Entomología, 36 (3-4): 417-426. 